\title{
Feedback from experimental isotopic compositions of used nuclear fuels on neutron cross sections and cumulative fission yields of the JEFF-3.1.1 library by using integral data assimilation
} \author{
Julie-Fiona Martin ${ }^{2}$ \\ ${ }^{1}$ CEA, DEN Cadarache, 13108 Saint Paul les Durance, France \\ 2 Orano Cycle, BU Recyclage, Paris, France
}

Axel Rizzo ${ }^{1, *}$, Claire Vaglio-Gaudard ${ }^{1}$, Gilles Noguere $^{1}$, Romain Eschbach ${ }^{1}$, Gabriele Grassi ${ }^{2}$, and

Received: 17 April 2019 / Received in final form: 11 October 2019 / Accepted: 21 November 2019

\begin{abstract}
Comparisons of calculated and experimental isotopic compositions of used nuclear fuels can provide valuable information on the quality of nuclear data involved in neutronic calculations. The experimental database used in the present study - containing more than a thousand isotopic ratio measurements for UOX and MOX fuels with burnup ranging from $10 \mathrm{GWd} / \mathrm{t}$ up to $85 \mathrm{GWd} / \mathrm{t}$ - allowed to investigate 45 isotopic ratios covering a large number of actinides (U, Np, Pu, Am and $\mathrm{Cm}$ ) and fission products (Nd, Cs, Sm, Eu, Gd, Ru, Ce, $\mathrm{Tc}, \mathrm{Mo}, \mathrm{Ag}$ and Rh). The Integral Data Assimilation procedure implemented in the CONRAD code was used to provide nuclear data trends with realistic uncertainties for Pressurized Water Reactors (PWRs) applications. Results confirm the quality of the ${ }^{235} \mathrm{U},{ }^{239} \mathrm{Pu}$ and ${ }^{241} \mathrm{Pu}$ neutron capture cross sections available in the JEFF3.1.1 library; slight increases of $+1.2 \pm 2.4 \%,+0.5 \pm 2.2 \%$ and $+1.2 \pm 4.2 \%$ are respectively suggested, these all being within the limits of the quoted uncertainties. Additional trends on the capture cross sections were also obtained for other actinides $\left({ }^{236} \mathrm{U},{ }^{238} \mathrm{Pu},{ }^{240} \mathrm{Pu},{ }^{242} \mathrm{Pu},{ }^{241} \mathrm{Am},{ }^{243} \mathrm{Am},{ }^{245} \mathrm{Cm}\right)$ and fission products $\left({ }^{103} \mathrm{Rh},{ }^{153} \mathrm{Eu}\right.$, $\left.{ }^{154} \mathrm{Eu}\right)$ as well as for the ${ }^{238} \mathrm{U}(\mathrm{n}, 2 \mathrm{n})$ and ${ }^{237} \mathrm{~Np}(\mathrm{n}, 2 \mathrm{n})$ reactions. Meaningful trends for the cumulative fission yields of ${ }^{144} \mathrm{Ce},{ }^{133} \mathrm{Cs},{ }^{137} \mathrm{Cs}$ and ${ }^{106} \mathrm{Ru}$ for the ${ }^{235} \mathrm{U}\left(\mathrm{n}_{\mathrm{th}}, \mathrm{f}\right)$ and ${ }^{239} \mathrm{Pu}\left(\mathrm{n}_{\mathrm{th}}, \mathrm{f}\right)$ reactions are also reported.
\end{abstract}

\section{Introduction}

Numerous studies report comparisons of calculated $(\mathrm{C})$ and experimental (E) isotopic compositions of used fuels for nuclear data validation purposes. In this work, we have used an experimental database that mainly contains proprietary data obtained from French PWRs fleet. Our database contains 1370 isotopic ratio measurements for UOX and MOX fuels with burnup ranging from $10 \mathrm{GWd} / \mathrm{t}$ up to $85 \mathrm{GWd} / \mathrm{t}$. It allows to investigate 45 isotopic ratios for a large number of actinides (U, Np, Pu, Am and $\mathrm{Cm}$ ) and fission products (Nd, Cs, Sm, Eu, Gd, Ru, Ce, Tc, Mo, $\mathrm{Ag}$ and $\mathrm{Rh}$ ).

Interpretations of post-irradiation experiments (PIEs) of samples irradiated in nuclear power reactors can be performed with the deterministic calculation package DARWIN2.3 [1], which is a calculation tool designed for fuel cycle applications. It solves the Boltzmann and Bateman equations to compute fuel cycle parameters at any irradiation and cooling time. A flow chart of the

\footnotetext{
* e-mail: axel.rizzo@cea.fr
}

DARWIN2.3 package for PWR calculations is presented in Figure 1 [1]. DARWIN2.3 includes the APOLLO2 deterministic transport code [2], which provides neutron data to the PEPIN2 depletion solver [3], namely selfshielded cross-sections libraries and multi-group neutron fluxes.

State-of-the-art calculated-to-experimental (C/E-1) ratios obtained with the JEFF-3.1.1 library [4] are summarized in reference [1]. The objectives of the present study are to include most of these $\mathrm{C} / \mathrm{E}-1$ ratios in the Integral Data Assimilation procedure of the CONRAD code $[5,6]$ and to provide valuable trends on the nuclear data compiled in the JEFF-3.1.1 library. Guidelines to achieve these objectives and strategies to take into account uncertainties coming from experiments, nuclear data and numerical biases are discussed in references [7-9]. The originality of our approach lies in the use of the AGS code method [10] to generate covariances between the C/E-1 ratios and of the marginalization procedure [11] to propagate uncertainties of "nuisance" parameters. Final results indicate that reliable trends can be obtained for the capture cross sections of some important actinides ${ }^{235} \mathrm{U},{ }^{236} \mathrm{U},{ }^{238} \mathrm{Pu},{ }^{239} \mathrm{Pu},{ }^{240} \mathrm{Pu},{ }^{241} \mathrm{Pu},{ }^{242} \mathrm{Pu},{ }^{241} \mathrm{Am}$, 


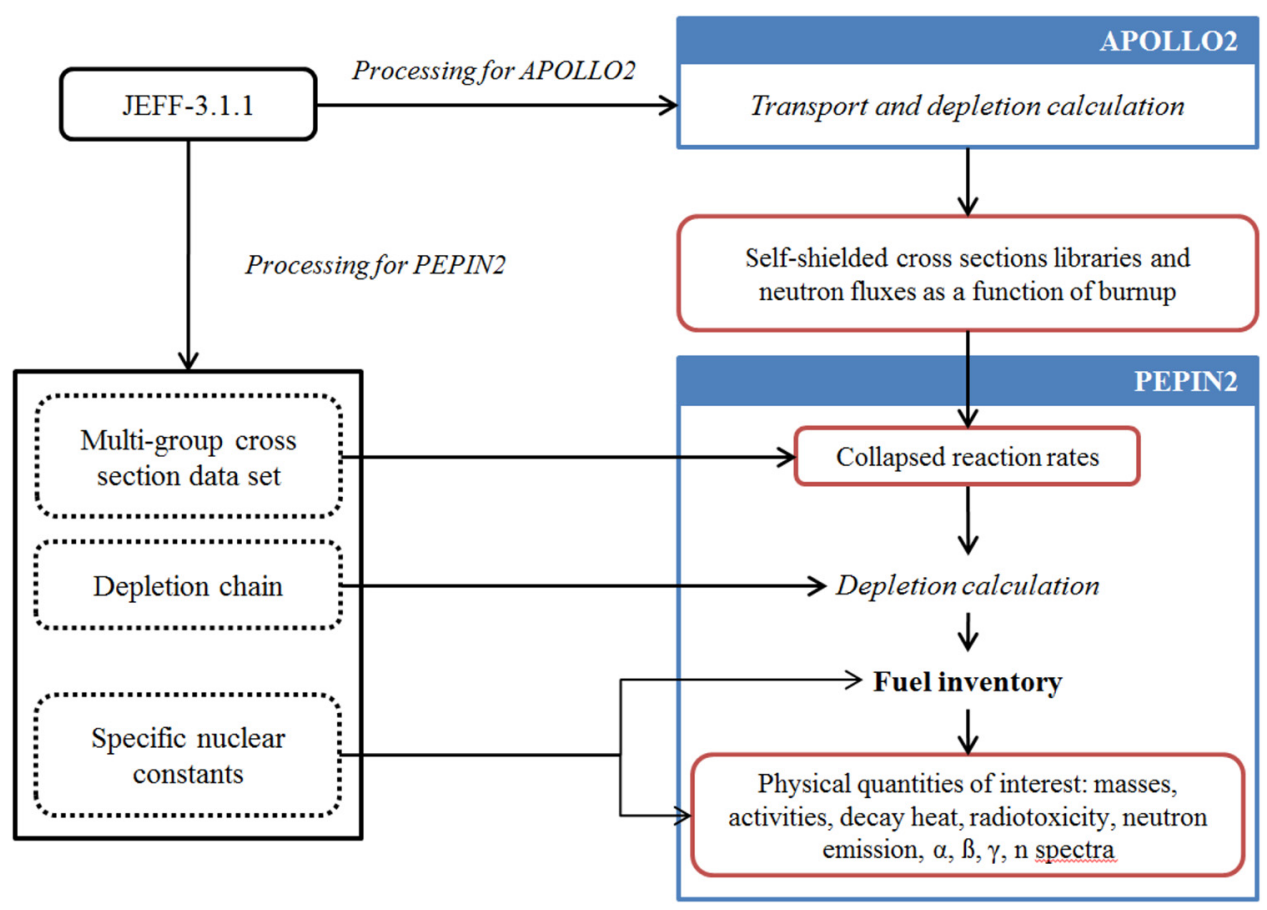

Fig. 1. Flow chart of the DARWIN2.3 package for PWR calculations.

$\left.{ }^{243} \mathrm{Am},{ }^{245} \mathrm{Cm}\right)$ and fission products $\left({ }^{103} \mathrm{Rh},{ }^{153} \mathrm{Eu},{ }^{154} \mathrm{Eu}\right)$ as well as for both ${ }^{238} \mathrm{U}(\mathrm{n}, 2 \mathrm{n})$ and ${ }^{237} \mathrm{~Np}(\mathrm{n}, 2 \mathrm{n})$ reactions. Meaningful trends can also be obtained for the cumulative fission yields of ${ }^{144} \mathrm{Ce},{ }^{133} \mathrm{Cs},{ }^{137} \mathrm{Cs}$ and ${ }^{106} \mathrm{Ru}$.

The integral data assimilation procedure is presented in Section 2, alongside free and nuisance parameters. Trends obtained on nuclear data are presented in Section 3 and discussed in Section 4.

\section{Integral Data Assimilation procedure}

The Integral Data Assimilation procedure implemented in the CONRAD code $[5,6]$ is based on a two-step calculation scheme. The first step is a least-square fitting procedure, namely the analytic resolution of a standard generalized least-square equation [12], that consists in adjusting model parameters (i.e. nuclear data) on a given set of integral values. The second step is a marginalization procedure designed to propagate nuisance parameter uncertainties after the fitting procedure.

\subsection{Governing equations}

For a correct use of the Integral Data Assimilation procedure of the CONRAD code, two types of model parameters have to be defined, namely observable and nuisance parameters. The observable parameters are free variables whose values are adjusted during the fitting procedure. The nuisance parameters are fixed model parameters with known uncertainties. Nuisance parameter uncertainties are taken into account via the marginalization technique [11]. The algorithm consists in building a "full" covariance matrix $\Sigma$ between the observable and nuisance parameters as follows [13]:

$$
\Sigma=\left(\begin{array}{cc}
M_{x, \text { Marg. }} & M_{x, \theta} \\
M_{x, \theta}{ }^{T} & M_{\theta}
\end{array}\right)
$$

where

$$
M_{x, \text { Marg. }}=M_{x}+\left(G_{x}^{T} G_{x}\right)^{-1} G_{x}^{T} G_{\theta} \cdot M_{\theta} \cdot G_{\theta}^{T} G_{x}\left(G_{x}^{T} G_{x}\right)^{-1}
$$

and

$$
M_{x, \theta}=-\left(G_{x}^{T} G_{x}\right)^{-1} G_{x}^{T} \cdot G_{\theta} \cdot M_{\theta},
$$

with $x$ being the set of adjusted parameters, $M_{x}$ being the posterior covariance matrix associated to $x, \theta$ being the set of nuisance parameters and $M_{\theta}$ the corresponding covariance matrix. Matrices $G_{x}$ and $G_{\theta}$ contain the partial derivatives of the calculated values with respect to the observable and nuisance parameters:

$$
\begin{gathered}
G_{x}(i, j)=\frac{\partial C_{i}}{\partial x_{j}}, \\
G_{\theta}(i, j)=\frac{\partial C_{i}}{\partial \theta_{j}} .
\end{gathered}
$$

\subsection{Used nuclear fuel data and uncertainties}

Integral values included in the fitting procedure are $\mathrm{C} / \mathrm{E}-1$ ratios obtained from the interpretation of PIEs with the 


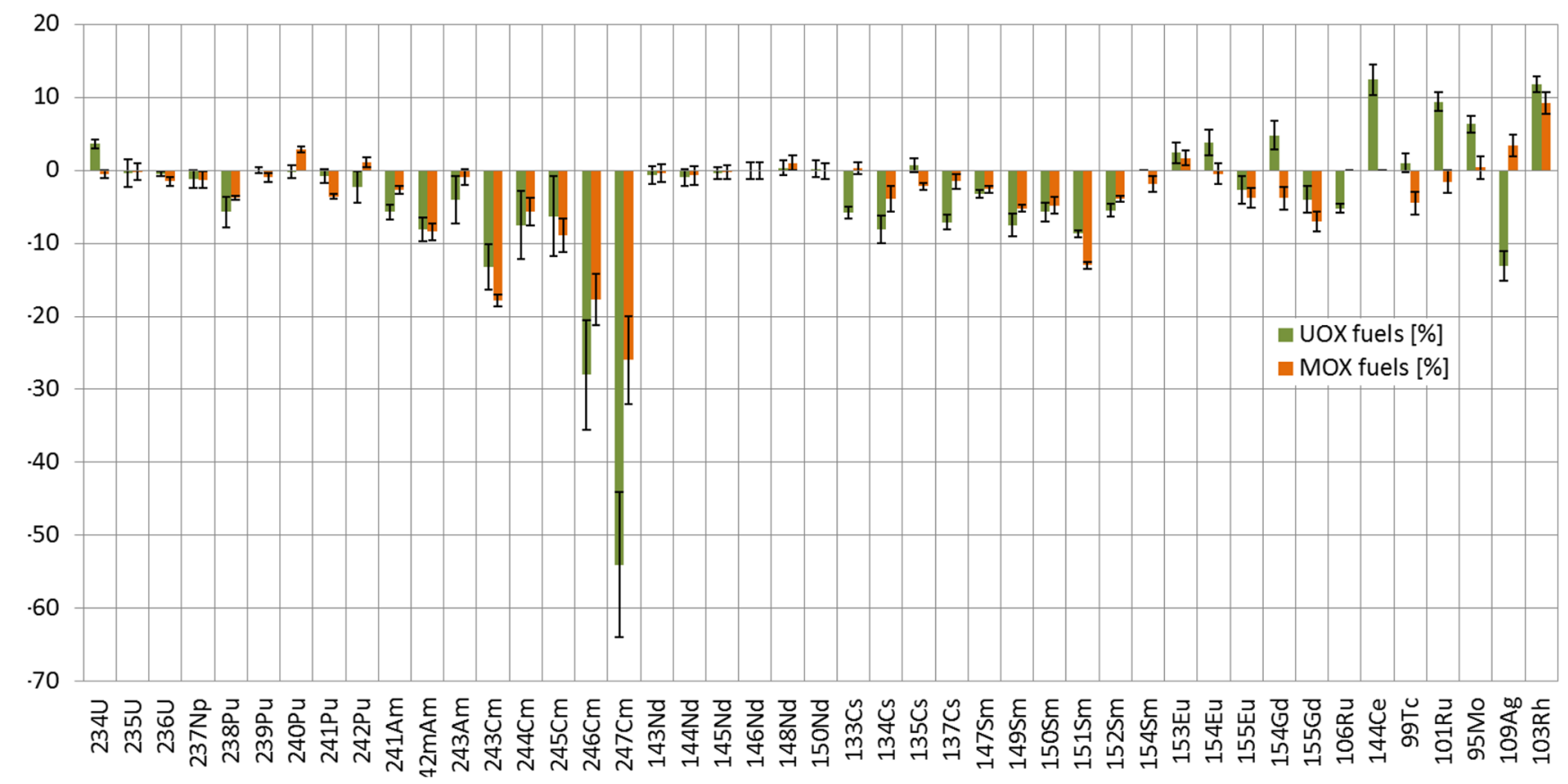

Fig. 2. Average calculated-to-experimental values $(\langle\mathrm{C} / \mathrm{E}\rangle-1)$ obtained for UOX and MOX fuels with the DARWIN2.3 package at $40 \mathrm{GWd} / \mathrm{t}$ using the JEFF-3.1.1 library.

DARWIN2.3 package [1] using the JEFF-3.1.1 library. Table 1 gives the nuclides for which $\mathrm{C} / \mathrm{E}-1$ values are available in the DARWIN2.3 validation suite, as well as the number and the type of fuel rod samples extracted per reactor. Examples of average $\langle\mathrm{C} / \mathrm{E}\rangle-1$ ratios at $40 \mathrm{GWd} / \mathrm{t}$ are given in Figure 2. This burnup is representative of the burnup of PWR assemblies at discharge. More information can be found in references [1,14]. According to data reported in Figure 2, the concentrations of the major actinides ${ }^{235} \mathrm{U},{ }^{239} \mathrm{Pu}$ and ${ }^{241} \mathrm{Pu}$ at $40 \mathrm{GWd} / \mathrm{t}$ are accurately calculated for UOX fuels with the JEFF-3.1.1 library. The mean $\langle\mathrm{C} / \mathrm{E}\rangle-1$ ratios are $-0.4 \pm 3.7 \%, 0.0 \pm 0.8 \%$ and $-0.8 \pm 1.8 \%$, respectively. Average results obtained for MOX fuels remain consistent within the quoted uncertainties, except for the ${ }^{241} \mathrm{Pu} /{ }^{238} \mathrm{U}$ ratio. For both types of fuel, the largest $\mathrm{C} / \mathrm{E}-1$ ratios are obtained for the curium isotopes. These discrepancies, reaching about $-50 \%$ for ${ }^{247} \mathrm{Cm}$ in UOX fuels, or discrepancies observed between UOX and MOX fuels, can be explained by using the Integral Data Assimilation procedure of the CONRAD code. The calculated-to-experimental ratios considered in this work share the same sources of systematic uncertainties (parameters $p_{1}$ to $p_{4}$ detailed in the next paragraph). Therefore, the AGS code method [10] has been used to estimate the covariance matrix $M_{C / E-1}$ between the C/E-1 values. The originality of the AGS code method is to combine uncorrelated and correlated uncertainties as follows:

$$
M_{C / E-1}=D+S . S^{T},
$$

in which $D$ is a $n \times n$ diagonal matrix containing the variances of the uncorrelated uncertainties and $S$ is a $n \times m$ rectangular matrix containing the correlated contributions for each of the $j \in \llbracket 1, m \rrbracket$ sources of uncertainty. No correlation between the experimental isotopic ratios was provided alongside the results of the chemical analyses. Therefore, the covariance matrix $D$ is a diagonal matrix that only contains the experimental uncertainties coming from the measurement process.

$$
D=\operatorname{diag}\left\{\operatorname{var}\left(C_{1} / E_{1}-1\right) \ldots \operatorname{var}\left(C_{n} / E_{n}-1\right)\right\},
$$

in which $\operatorname{var}\left(C_{i} / E_{i}-1\right)$ represents the uncertainty associated with the $i$ th experiment. For the $S$-matrix, four sources of systematic uncertainties are considered:

$$
S=\left(\begin{array}{cccc}
\Delta_{1,1} & \Delta_{2,1} & \Delta_{3,1} & \Delta_{4,1} \\
\vdots & \vdots & \vdots & \vdots \\
\Delta_{1, n} & \Delta_{2, n} & \Delta_{3, n} & \Delta_{4, n}
\end{array}\right)
$$

with:

$$
\Delta_{k, i}=\frac{\partial C_{i}}{\partial p_{k}} \Delta p_{k}
$$

Parameters $p_{1}$ and $p_{2}$ are related to the fuel and moderator temperatures, respectively. Their contributions $\Delta_{1, i}$ and $\Delta_{2, i}$ are calculated with DARWIN2.3 from direct perturbations of the parameters, by considering an uncertainty of $\pm 50^{\circ} \mathrm{C}$ for the fuel temperature and $\pm 2{ }^{\circ} \mathrm{C}$ for the moderator temperature at $1 \sigma$. Parameters $p_{3}$ and $p_{4}$ are numerical scheme-related uncertainties, depending on the use of DARWIN2.3. The former corresponds to the differences that could be obtained between deterministic and Monte-Carlo calculation schemes. It was estimated 


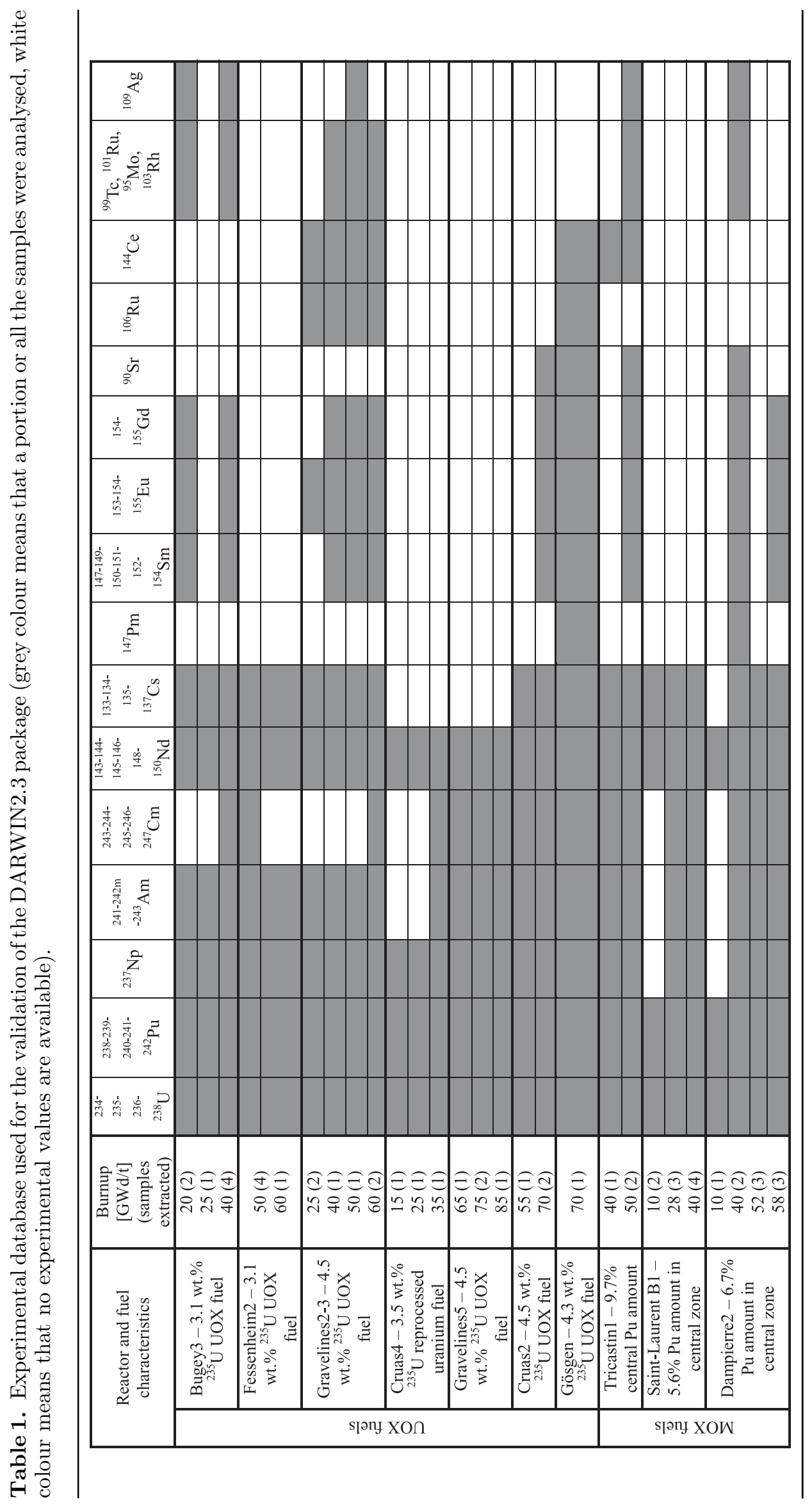




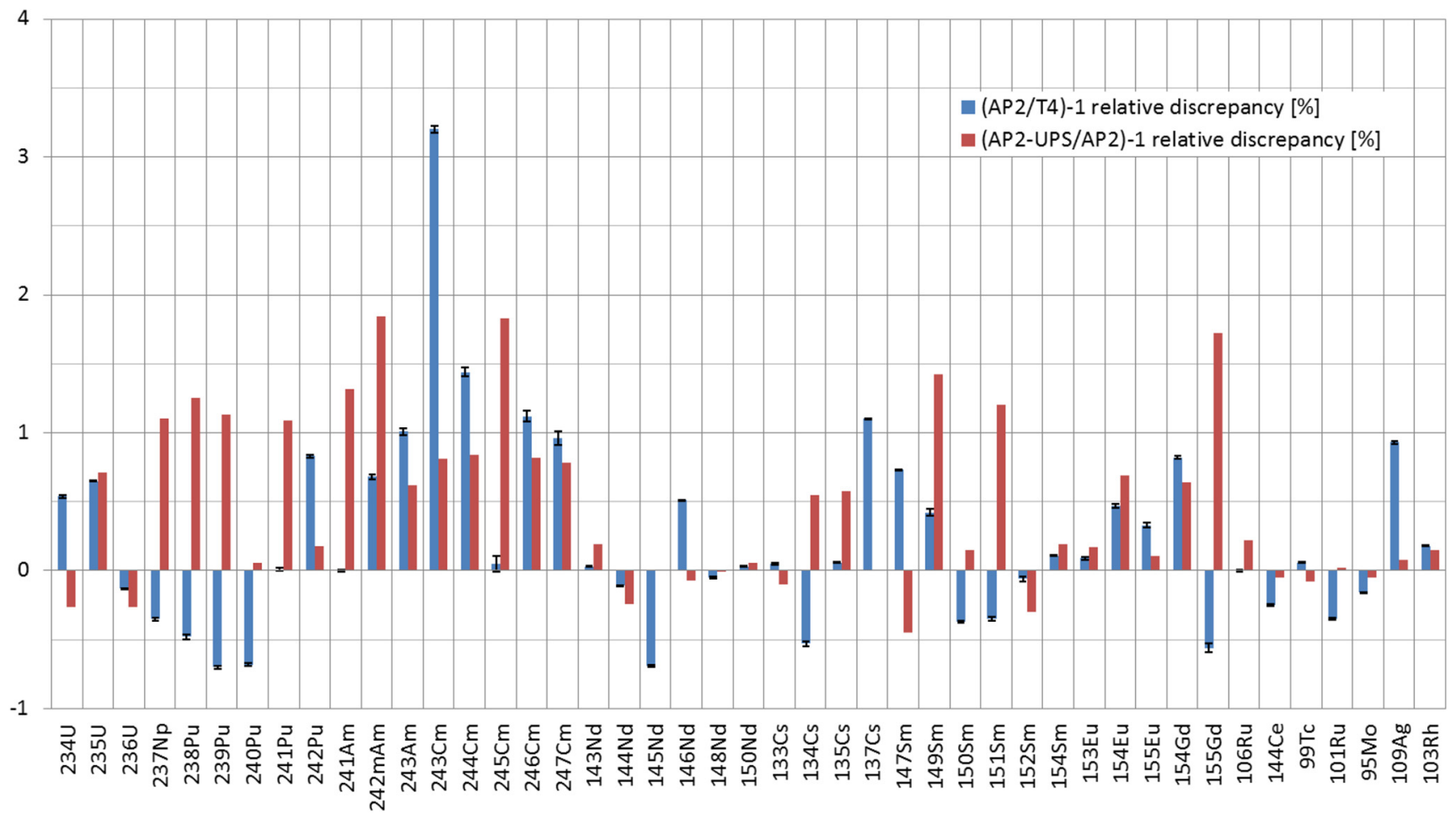

Fig. 3. Differences obtained on the isotopic concentrations (normalized to ${ }^{238} \mathrm{U}$ concentration) on a pin-cell geometry for a $3.7 \%{ }^{235} \mathrm{U}$ enriched UOX fuel at $40 \mathrm{GWd} / \mathrm{t}$ between i) in blue: APOLLO2 (AP2) and TRIPOLI-4 depletion calculations (T4), ii) in red: two APOLLO2 depletion calculations, with (AP2-UPS) and without (AP2) resonant up-scattering effects. Error bars represent the statistical uncertainty provided by the TRIPOLI-4 calculations.

from pin-cell depletion calculations performed with the deterministic code APOLLO2 and the Monte-Carlo code TRIPOLI-4 [15], with the same filiation chain. The latter corresponds to the differences due to resonant upscattering effects [16] on fuel inventory calculations. Examples of differences obtained on the calculated isotopic ratios for a UOX fuel $\left(3.7 \mathrm{wt} . \%{ }^{235} \mathrm{U}\right)$ at $40 \mathrm{GWd} / \mathrm{t}$ are given in Figure 3. Most of the obtained differences lie below $1 \%$. The comparison of the deterministic and Monte-Carlo calculations schemes indicates that the differences are significant for the curium isotopes and non-negligible for ${ }^{137} \mathrm{Cs}$. Among the fission products, ${ }^{137} \mathrm{Cs}$ seems to be an isolated case needing more extensive studies. As expected, in the case of the up-scattering effect, non-negligible increases of the concentration of all the actinides are observed. The final correlation matrix between the C/E-1 values reconstructed with the AGS code method (Eq. (6)) is shown in Figure 4. An interesting feature is the correlations between the UOX and MOX fuel data that introduces constraints on the variations of the observable parameters during the fitting procedure.

\subsection{Observable parameters}

Isotopic ratios depend on a wide number of nuclear data. Therefore, the CYRUS tool [17] was used, coupled with PEPIN2 depletion solver, to establish an exhaustive list of nuclear data involved in the build-up of actinides and fission products.
The selected set of observable parameters that will be adjusted with the CONRAD code is given in Table 2. It was chosen not to adjust fission cross sections, because it would imply modifying the burnup of the analysed samples. This is incompatible with the fact that the burnup is a fixed parameter for each sample with a known uncertainty of about $\pm 2 \%$ (see next section). It was also decided not to fit the decay constants; in our study, decay constants of interest are well known, with quoted uncertainties lesser than $0.6 \%$ (see Tab. 3). Eventually, it was chosen not to fit some nuclear data (e.g. fission yields on samarium isotopes, or samarium cross sections) because the number of free parameters was too important with respect to the number of constraints, thus leading to an underdetermined system.

Parameter $y_{c}(X, A)$ indicates the thermal cumulative fission yield of nuclide $X$ for actinide $A$. For reducing the number of free parameters, the $(\mathrm{n}, \gamma)$ and $(\mathrm{n}, 2 \mathrm{n})$ cross sections are effective cross sections which are averaged over the neutron flux $\varphi(E)$ :

$$
\bar{\sigma}=\frac{\int_{0}^{+\infty} \sigma(E) \varphi(E) d E}{\int_{0}^{+\infty} \varphi(E) d E} .
$$

Prior uncertainties for neutron cross sections come from the COMAC-V2.0 covariance matrix database $[18,19]$, developed at CEA Cadarache. For fission yields, they come from the JEFF-3.1.1 library. 


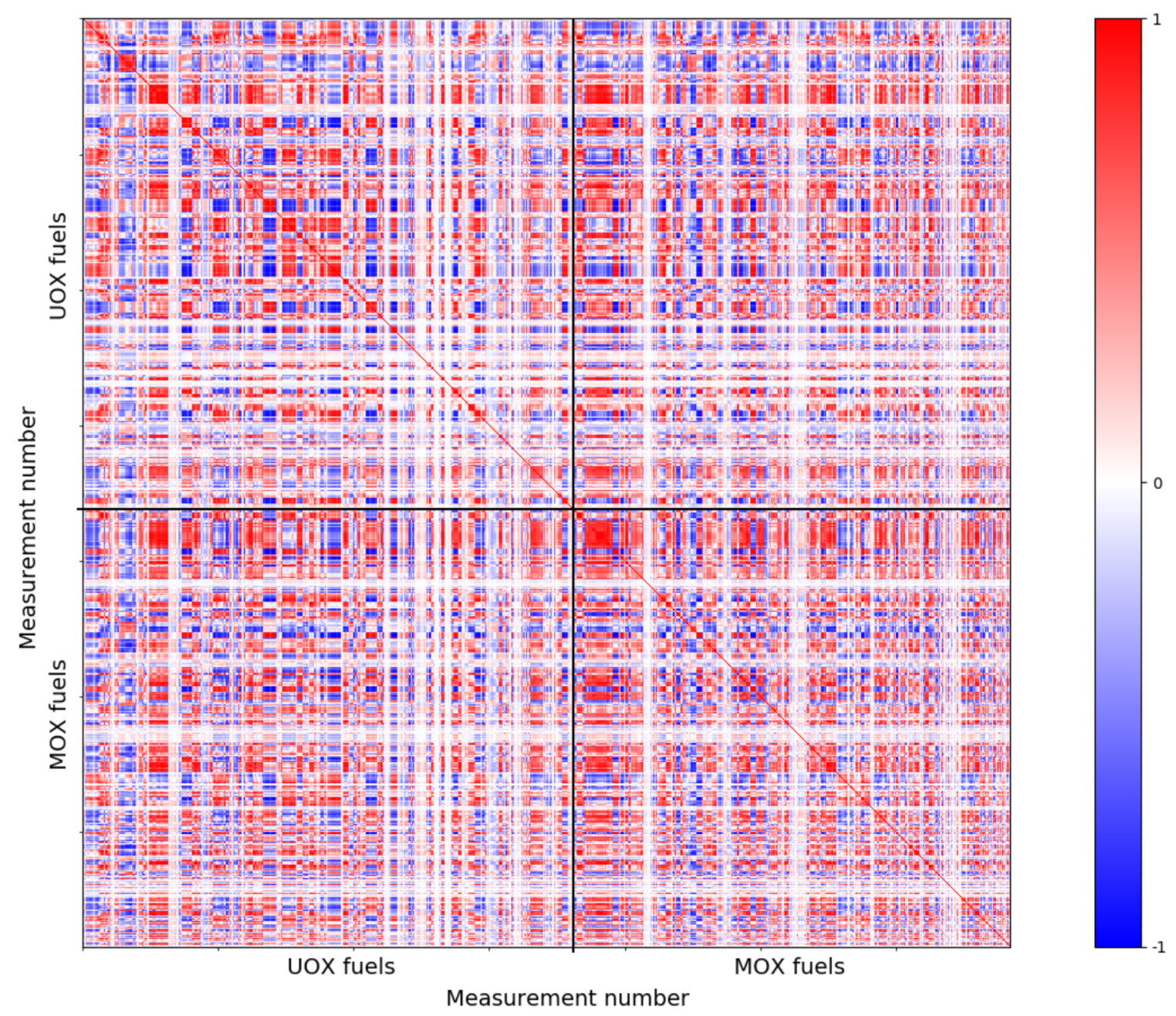

Fig. 4. Correlation matrix between calculated-to-experimental isotopic ratios used for the assimilation procedure.

\subsection{Nuisance parameters}

Nuisance parameters are fixed parameters whose uncertainties are propagated via the marginalization procedure of the CONRAD code (Sect. 2.1). The list of the nuisance parameters introduced in the CONRAD calculation is given in Table 3. It gathers all nuclear data involved in the buildup of nuclides considered, determined with the CYRUS tool, except the ones fitted (see previous section). The cross section uncertainties come from the COMAC-V2.0 database. Uncertainties for the decay data (periods, isomeric ratios and branching ratios) and fission yields are directly taken from the JEFF-3.1.1 library.

Nuisance parameters are not only the nuclear data involved in the build-up of actinides and fission products, but also experimental parameters such as the burnup scaling parameter. The relative uncertainty associated to the latter parameter is close to $\pm 2 \%$.

\section{Nuclear data adjustment trends and uncertainties}

Nuclear data adjustment trends provided by the Integral Data Assimilation of our used nuclear fuel database are reported in Table 4. Results are listed by ascending order of adjustment coefficient. In particular, those obtained for the europium capture cross sections and cumulative fission yield of ${ }^{137} \mathrm{Cs}$ confirm the results previously reported in references $[8,9]$.

Table 4 also compares the relative uncertainties obtained before and after the marginalization of the nuisance parameters (Sect. 2.4). For most of the posterior values, the fitting uncertainties are lower than $1 \%$. The marginalization provides more realistic uncertainties that allow discussing the quality of some cumulative fission yields and cross sections recommended in the JEFF-3.1.1 library and hence the content of the covariance database COMAC-V2.0.

\subsection{Cumulative fission yields}

Adjustment trends on a few number of cumulative fission yields were extracted from the Integral Data Assimilation of our used nuclear fuel data. This work provide information on the cumulative fission yields of ${ }^{106} \mathrm{Ru}$, ${ }^{144} \mathrm{Ce},{ }^{133} \mathrm{Cs}$ and ${ }^{137} \mathrm{Cs}$ for both ${ }^{235} \mathrm{U}(\mathrm{n}, \mathrm{f})$ and ${ }^{239} \mathrm{Pu}(\mathrm{n}, \mathrm{f})$ reactions with relative uncertainties ranging from $1.3 \%$ to $5.7 \%$. These trends can be directly applied to the 
Table 2. Fitted parameters, relative prior uncertainty and origin of the uncertainty.

\begin{tabular}{lll}
\hline $\begin{array}{l}\text { Model } \\
\text { parameter }\end{array}$ & $\begin{array}{l}\text { Prior } \\
\text { uncertainty [\%] }\end{array}$ & $\begin{array}{l}\text { Origin of the } \\
\text { uncertainty }\end{array}$ \\
\hline${ }^{235} \mathrm{U}(\mathrm{n}, \gamma)$ & $1.4 \%$ & COMAC-V2.0 \\
${ }^{236} \mathrm{U}(\mathrm{n}, \gamma)$ & $3.8 \%$ & COMAC-V2.0 \\
${ }^{238} \mathrm{U}(\mathrm{n}, \mathrm{xn})$ & $8.5 \%$ & COMAC-V2.0 \\
${ }^{237} \mathrm{~Np}(\mathrm{n}, \mathrm{xn})$ & $20 \%$ & COMAC-V2.0 \\
${ }^{238} \mathrm{Pu}(\mathrm{n}, \gamma)$ & $9.8 \%$ & COMAC-V2.0 \\
${ }^{239} \mathrm{Pu}(\mathrm{n}, \gamma)$ & $2.2 \%$ & COMAC-V2.0 \\
${ }^{240} \mathrm{Pu}(\mathrm{n}, \gamma)$ & $1.9 \%$ & COMAC-V2.0 \\
${ }^{241} \mathrm{Pu}(\mathrm{n}, \gamma)$ & $2.3 \%$ & COMAC-V2.0 \\
${ }^{242} \mathrm{Pu}(\mathrm{n}, \gamma)$ & $12 \%$ & COMAC-V2.0 \\
${ }^{241} \mathrm{Am}(\mathrm{n}, \gamma)$ & $2.8 \%$ & COMAC-V2.0 \\
${ }^{243} \mathrm{Am}(\mathrm{n}, \gamma)$ & $3.6 \%$ & COMAC-V2.0 \\
${ }^{242} \mathrm{Cm}(\mathrm{n}, \gamma)$ & $15 \%$ & COMAC-V2.0 \\
${ }^{244} \mathrm{Cm}(\mathrm{n}, \gamma)$ & $15 \%$ & COMAC-V2.0 \\
${ }^{245} \mathrm{Cm}(\mathrm{n}, \gamma)$ & $15 \%$ & COMAC-V2.0 \\
${ }^{246} \mathrm{Cm}(\mathrm{n}, \gamma)$ & $7.6 \%$ & COMAC-V2.0 \\
${ }^{247} \mathrm{Cm}(\mathrm{n}, \gamma)$ & $13 \%$ & COMAC-V2.0 \\
${ }^{99} \mathrm{Tc}(\mathrm{n}, \gamma)$ & $1.8 \%$ & COMAC-V2.0 \\
${ }^{103} \mathrm{Rh}(\mathrm{n}, \gamma)$ & $4.0 \%$ & COMAC-V2.0 \\
$y_{c}\left({ }^{106} \mathrm{Ru},{ }^{239} \mathrm{Pu}\right)$ & $2.2 \%$ & JEFF-3.1.1 \\
$y_{c}\left({ }^{133} \mathrm{Cs},{ }^{235} \mathrm{U}\right)$ & $1.6 \%$ & JEFF-3.1.1 \\
$y_{c}\left({ }^{133} \mathrm{Cs},{ }^{239} \mathrm{Pu}\right)$ & $1.8 \%$ & JEFF-3.1.1 \\
${ }^{133} \mathrm{Cs}(\mathrm{n}, \gamma)$ & $5.2 \%$ & COMAC-V2.0 \\
$y_{c}\left({ }^{137} \mathrm{Cs},{ }^{235} \mathrm{U}\right)$ & $1.5 \%$ & COMAC-V2.0 \\
$y_{c}\left({ }^{137} \mathrm{Cs},{ }^{239} \mathrm{Pu}\right)$ & $1.4 \%$ & COMAC-V2.0 \\
$y_{c}\left({ }^{144} \mathrm{Ce},{ }^{235} \mathrm{U}\right)$ & $1.0 \%$ & JEFF-3.1.1 \\
$y_{c}\left({ }^{144} \mathrm{Ce},{ }^{239} \mathrm{Pu}\right)$ & $0.8 \%$ & JEFF-3.1.1 \\
${ }^{153} \mathrm{Eu}(\mathrm{n}, \gamma)$ & $5.0 \%$ & COMAC-V2.0 \\
${ }^{154} \mathrm{Eu}(\mathrm{n}, \gamma)$ & $12 \%$ & \\
\hline & &
\end{tabular}

cumulative fission yields recommended in the JEFF-3.1.1 library. For ${ }^{235} \mathrm{U}$, adjustment trends reported in Table 4 provide the following results:

$$
\begin{aligned}
& y_{c}\left({ }^{144} \mathrm{Ce},{ }^{235} \mathrm{U}\right)=0.0524 \pm 0.0018(3.4 \%), \\
& y_{c}\left({ }^{133} \mathrm{Cs},{ }^{235} \mathrm{U}\right)=0.0701 \pm 0.0014(2.0 \%), \\
& y_{c}\left({ }^{137} \mathrm{Cs},{ }^{235} \mathrm{U}\right)=0.0669 \pm 0.0013(1.9 \%) .
\end{aligned}
$$

For ${ }^{239} \mathrm{Pu}$, the following results are obtained:

$y_{c}\left({ }^{144} \mathrm{Ce}{ }^{239} \mathrm{Pu}\right)=0.0345 \pm 0.0005(1.3 \%)$,

$y_{c}\left({ }^{133} \mathrm{Cs},{ }^{239} \mathrm{Pu}\right)=0.0690 \pm 0.0021(3.1 \%)$,

$y_{c}\left({ }^{137} \mathrm{Cs},{ }^{239} \mathrm{Pu}\right)=0.0654 \pm 0.0021(3.1 \%)$,

$y_{c}\left({ }^{106} \mathrm{Ru},{ }^{239} \mathrm{Pu}\right)=0.0457 \pm 0.0026(5.7 \%)$.

Comparisons with evaluated values and data available in the literature are reported in Section 4.

\subsection{Neutron cross sections}

Results obtained for the $(\mathrm{n}, \gamma)$ and $(\mathrm{n}, 2 \mathrm{n})$ reactions can be divided in three groups.

- The first group concerns the reactions for which the adjustment trends remain within the uncertainties obtained after marginalization. This can be observed for six actinides and two fission products: ${ }^{235} \mathrm{U}(\mathrm{n}, \gamma)$, ${ }^{236} \mathrm{U}(\mathrm{n}, \gamma),{ }^{239} \mathrm{Pu}(\mathrm{n}, \gamma),{ }^{241} \mathrm{Pu}(\mathrm{n}, \gamma),{ }^{244} \mathrm{Cm}(\mathrm{n}, \gamma),{ }^{246} \mathrm{Cm}(\mathrm{n}, \gamma)$, ${ }^{133} \mathrm{Cs}(\mathrm{n}, \gamma)$ and ${ }^{99} \mathrm{Tc}(\mathrm{n}, \gamma)$. The case of technetium should be considered with caution because of the large uncertainty obtained $( \pm 7.8 \%)$. This first group refers to reactions that are correctly described in JEFF-3.1.1 or for which minor corrections are expected.

- The second group concerns the reactions for which the adjustment trends are higher than the uncertainty obtained after marginalization, while remaining lower than $5 \%$. This is the case of three actinides: ${ }^{238} \mathrm{U}(\mathrm{n}, 2 \mathrm{n})$, ${ }^{240} \mathrm{Pu}(\mathrm{n}, \gamma)$ and ${ }^{242} \mathrm{Pu}(\mathrm{n}, \gamma)$.

- The third group concerns the reactions for which the adjustment trends are higher than the uncertainty obtained after marginalization and also higher than $5 \%$. Six actinides and three fission products fulfil these conditions: ${ }^{237} \mathrm{~Np}(\mathrm{n}, 2 \mathrm{n}),{ }^{241} \mathrm{Am}(\mathrm{n}, \gamma),{ }^{243} \mathrm{Am}(\mathrm{n}, \gamma)$, ${ }^{242} \mathrm{Cm}(\mathrm{n}, \gamma),{ }^{245} \mathrm{Cm}(\mathrm{n}, \gamma),{ }^{247} \mathrm{Cm}(\mathrm{n}, \gamma),{ }^{153} \mathrm{Eu}(\mathrm{n}, \gamma),{ }^{154} \mathrm{Eu}(\mathrm{n}, \gamma)$ and ${ }^{103} \operatorname{Rh}(\mathrm{n}, \gamma)$. Results obtained for the ${ }^{247} \mathrm{Cm}(\mathrm{n}, \gamma)$ and ${ }^{237} \mathrm{~Np}(\mathrm{n}, 2 \mathrm{n})$ reactions only indicate that such reactions are poorly known. Our used nuclear fuel data cannot provide accurate information to improve them. This latest group provides key information on reactions that have to be corrected in priority for improving significantly the DARWIN2.3 calculations for fuel cycle applications. However, adjustment trends reported in Table 4 need to be interpreted by examining the evolution with the burnup of the posterior calculated-to-experimental ratios provided by CONRAD at the end of the Integral Data Assimilation procedure. ${ }^{241} \mathrm{Am}$ and ${ }^{243} \mathrm{Am}$ are discussed below.

Figures 5 and 6 show the prior and posterior $\mathrm{C} / \mathrm{E}-1$ values for the ratio ${ }^{241} \mathrm{Am} /{ }^{238} \mathrm{U}$ in UOX and MOX fuels respectively, from $20 \mathrm{GWd} / \mathrm{t}$ to $85 \mathrm{GWd} / \mathrm{t}$. The review of the posterior results reveals a slight improvement in average for UOX fuels, while the average $\mathrm{C} / \mathrm{E}$ discrepancy is slightly degraded for MOX fuels. This result might be explained by the non-negligible dispersion of the calculated-to-experimental values, especially for MOX fuels. Final uncertainties in Table 4 do not reflect the potential inconsistencies between the used nuclear fuel data.

The production chain of ${ }^{244} \mathrm{Cm}$ (Fig. 7) shows that the impact of ${ }^{243} \mathrm{Am}$ capture cross section can be quantified on the calculated-to-experimental ratios of ${ }^{244} \mathrm{Cm} /{ }^{238} \mathrm{U}$. The prior and posterior $\mathrm{C} / \mathrm{E}-1$ values for UOX and MOX fuels are reported in Figures 8 and 9. The posterior values are closer to zero in average. However, a dependence of the results with the burnup can be observed. Below approximately $30 \mathrm{GWd} / \mathrm{t}$, the ${ }^{244} \mathrm{Cm} /{ }^{238} \mathrm{U}$ ratio is still underestimated. This could be explained by the low amount of ${ }^{244} \mathrm{Cm}$ in the fuel at low burnup, suggesting that the experimental values at low burnup should be considered with caution. Hence, when considering only high burnup data on Figures 8 and 9, for which the ${ }^{244} \mathrm{Cm}$ content becomes more significant, one can observe a slight overestimation of the ${ }^{244} \mathrm{Cm} /{ }^{238} \mathrm{U}$ isotopic ratio. This indicates that the increase of the ${ }^{243} \mathrm{Am}$ capture cross section suggested in Table 4 is overcompensating the initial $\mathrm{C} / \mathrm{E}-1$ values. In that case, the obtained adjustment trend of $+9.4 \pm 2.2 \%$ should be considered as an upper limit. 


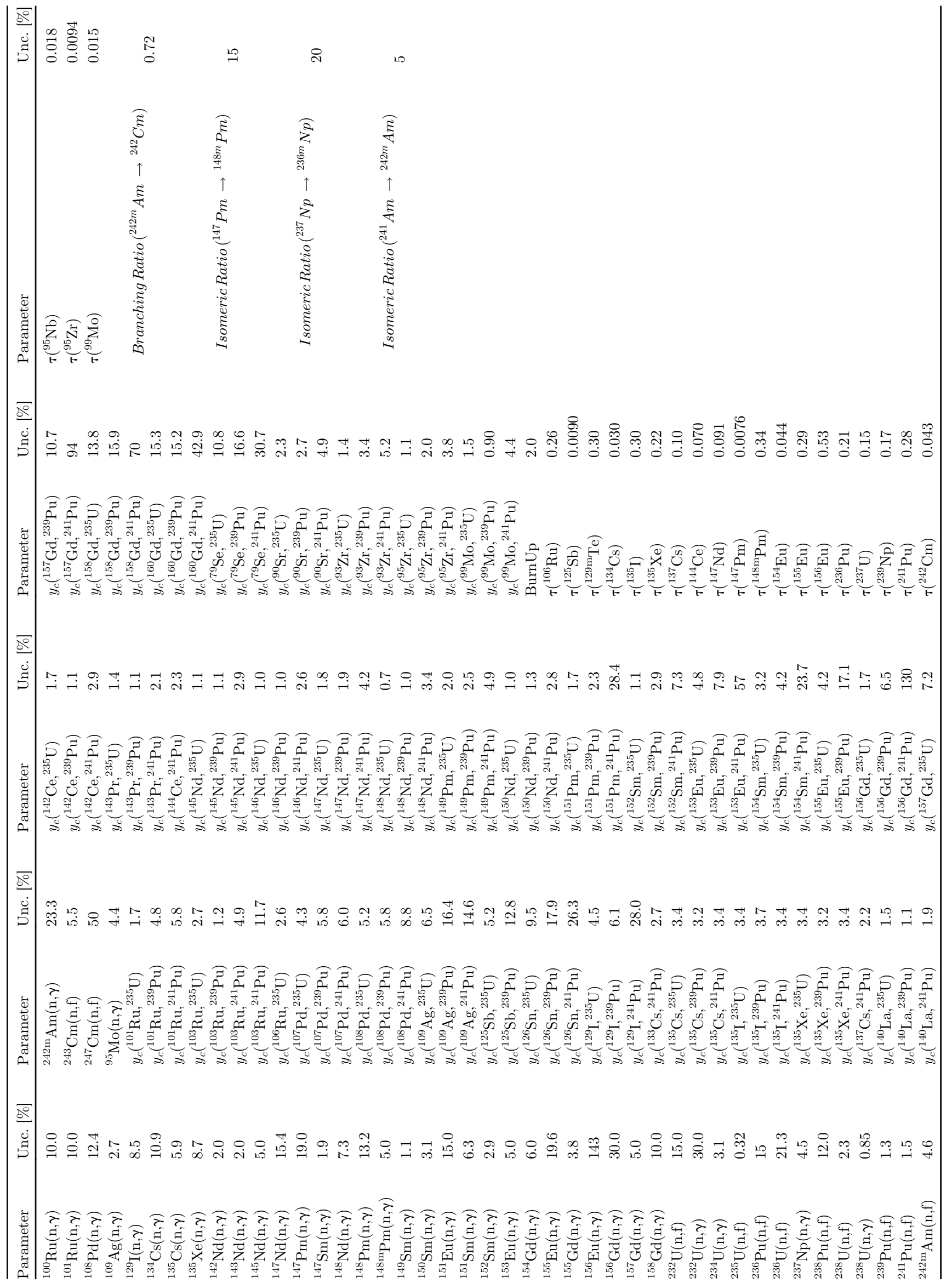


Table 4. Nuclear data adjustment trends obtained from the Integral Data Assimilation of the C/E-1 values reported in reference [3].

\begin{tabular}{|c|c|c|c|}
\hline \multirow[t]{2}{*}{ Fitted nuclear data } & \multirow[t]{2}{*}{ Prior uncertainty } & \multicolumn{2}{|c|}{ Mean posterior value and associated uncertainty } \\
\hline & & After fit & After fit and marginalization \\
\hline$y_{c}\left({ }^{144} \mathrm{Ce},{ }^{239} \mathrm{Pu}\right)$ & $0.8 \%$ & $-8.0 \pm 0.5 \%$ & $-8.0 \pm 1.3 \%$ \\
\hline${ }^{238} \mathrm{Pu}(\mathrm{n}, \gamma)$ & $9.8 \%$ & $-7.5 \pm 0.2 \%$ & $-7.5 \pm 7.0 \%$ \\
\hline$y_{c}\left({ }^{144} \mathrm{Ce},{ }^{235} \mathrm{U}\right)$ & $1.0 \%$ & $-4.6 \pm 0.9 \%$ & $-4.6 \pm 3.3 \%$ \\
\hline$y_{c}\left({ }^{133} \mathrm{Cs},{ }^{239} \mathrm{Pu}\right)$ & $1.8 \%$ & $-1.4 \pm 0.08 \%$ & $-1.4 \pm 3.1 \%$ \\
\hline${ }^{244} \mathrm{Cm}(\mathrm{n}, \gamma)$ & $15 \%$ & $+0.2 \pm 0.06 \%$ & $+0.2 \pm 1.0 \%$ \\
\hline${ }^{239} \mathrm{Pu}(\mathrm{n}, \gamma)$ & $2.2 \%$ & $+0.5 \pm 0.02 \%$ & $+0.5 \pm 2.2 \%$ \\
\hline$y_{c}\left({ }^{137} \mathrm{Cs},{ }^{239} \mathrm{Pu}\right)$ & $1.4 \%$ & $+1.0 \pm 0.09 \%$ & $+1.0 \pm 3.1 \%$ \\
\hline${ }^{241} \mathrm{Pu}(\mathrm{n}, \gamma)$ & $2.3 \%$ & $+1.2 \pm 0.03 \%$ & $+1.2 \pm 4.2 \%$ \\
\hline${ }^{235} \mathrm{U}(\mathrm{n}, \gamma)$ & $1.4 \%$ & $+1.2 \pm 0.02 \%$ & $+1.2 \pm 2.4 \%$ \\
\hline${ }^{133} \operatorname{Cs}(\mathrm{n}, \gamma)$ & $5.2 \%$ & $+1.9 \pm 0.06 \%$ & $+1.9 \pm 2.0 \%$ \\
\hline${ }^{99} \mathrm{Tc}(\mathrm{n}, \gamma)$ & $1.8 \%$ & $+2.2 \pm 0.8 \%$ & $+2.2 \pm 7.8 \%$ \\
\hline${ }^{236} \mathrm{U}(\mathrm{n}, \gamma)$ & $3.8 \%$ & $+2.2 \pm 0.1 \%$ & $+2.2 \pm 1.9 \%$ \\
\hline${ }^{246} \mathrm{Cm}(\mathrm{n}, \gamma)$ & $7.6 \%$ & $+3.2 \pm 0.5 \%$ & $+3.2 \pm 4.0 \%$ \\
\hline${ }^{242} \mathrm{Pu}(\mathrm{n}, \gamma)$ & $12 \%$ & $+3.8 \pm 0.04 \%$ & $+3.8 \pm 2.8 \%$ \\
\hline${ }^{240} \mathrm{Pu}(\mathrm{n}, \gamma)$ & $1.9 \%$ & $+4.2 \pm 0.03 \%$ & $+4.2 \pm 2.8 \%$ \\
\hline${ }^{238} \mathrm{U}(\mathrm{n}, 2 \mathrm{n})$ & $8.5 \%$ & $+4.8 \pm 0.3 \%$ & $+4.8 \pm 2.0 \%$ \\
\hline${ }^{153} \operatorname{Eu}(\mathrm{n}, \gamma)$ & $5.0 \%$ & $+5.1 \pm 0.08 \%$ & $+5.1 \pm 2.4 \%$ \\
\hline$y_{c}\left({ }^{133} \mathrm{Cs},{ }^{235} \mathrm{U}\right)$ & $1.6 \%$ & $+6.2 \pm 0.09 \%$ & $+6.2 \pm 2.0 \%$ \\
\hline${ }^{103} \operatorname{Rh}(\mathrm{n}, \gamma)$ & $4.0 \%$ & $+7.4 \pm 1.0 \%$ & $+7.4 \pm 4.7 \%$ \\
\hline$y_{c}\left({ }^{137} \mathrm{Cs},{ }^{235} \mathrm{U}\right)$ & $1.5 \%$ & $+7.5 \pm 0.1 \%$ & $+7.5 \pm 1.9 \%$ \\
\hline${ }^{154} \mathrm{Eu}(\mathrm{n}, \gamma)$ & $12 \%$ & $+8.4 \pm 0.09 \%$ & $+8.4 \pm 3.7 \%$ \\
\hline$y_{c}\left({ }^{106} \mathrm{Ru},{ }^{239} \mathrm{Pu}\right)$ & $2.2 \%$ & $+9.2 \pm 0.5 \%$ & $+9.2 \pm 5.7 \%$ \\
\hline${ }^{243} \operatorname{Am}(\mathrm{n}, \gamma)$ & $3.7 \%$ & $+9.4 \pm 0.05 \%$ & $+9.4 \pm 2.2 \%$ \\
\hline${ }^{241} \mathrm{Am}(\mathrm{n}, \gamma)$ & $2.8 \%$ & $+10.7 \pm 0.1 \%$ & $+10.7 \pm 4.7 \%$ \\
\hline${ }^{245} \mathrm{Cm}(\mathrm{n}, \gamma)$ & $15 \%$ & $+11.4 \pm 0.07 \%$ & $+11.4 \pm 2.8 \%$ \\
\hline${ }^{242} \mathrm{Cm}(\mathrm{n}, \gamma)$ & $15 \%$ & $+18.2 \pm 0.07 \%$ & $+18.2 \pm 4.8 \%$ \\
\hline${ }^{237} \mathrm{~Np}(\mathrm{n}, 2 \mathrm{n})$ & $20 \%$ & $+41 \pm 1 \%$ & $+41 \pm 20 \%$ \\
\hline${ }^{247} \mathrm{Cm}(\mathrm{n}, \gamma)$ & $13 \%$ & $+98 \pm 5.1 \%$ & $+98 \pm 73 \%$ \\
\hline
\end{tabular}

\subsection{Feedback on the COMAC-V2.0 library}

Results reported in Table 4 can be used to assess the quality of the COMAC-V2.0 database: the mean posterior values obtained in this work should presumably remain within the limit of the prior uncertainties provided by COMAC-V2.0, otherwise the latter is underestimated. On the contrary, a prior uncertainty value which is significantly larger than the posterior trend may indicate that the prior uncertainty is overestimated.

When comparing the posterior values with the prior uncertainties, it seems indeed that the prior uncertainties for the capture cross sections of ${ }^{133} \mathrm{Cs},{ }^{236} \mathrm{U},{ }^{242} \mathrm{Pu},{ }^{244} \mathrm{Cm}$ and ${ }^{246} \mathrm{Cm}$ are overestimated. As an example, the COMAC-V2.0 library provides a relative uncertainty for the ${ }^{242} \mathrm{Pu}(\mathrm{n}, \gamma)$ reaction which is close to $12 \%$, while the present study suggests a slight increase of the capture cross section of $+3.8 \pm 2.8 \%$. On the other hand, the COMAC-V2.0 database seems to underestimate the uncertainties of the ${ }^{103} \mathrm{Rh}(\mathrm{n}, \gamma),{ }^{241} \mathrm{Am}(\mathrm{n}, \gamma)$ and ${ }^{243} \mathrm{Am}(\mathrm{n}, \gamma)$ reactions. This feedback constitutes guidelines for the improvement of the COMAC-V2.0 database.

\section{Discussions of the results}

Results provided by the Integral Data Assimilation procedure and presented in Section 3 were obtained using the JEFF-3.1.1 library. Since its official release in 2009, numerous validation studies were conducted on this library; furthermore new experimental data and evaluated nuclear data files are now available in the literature. This section compares results obtained in the present work with those reported in the literature and the international libraries in order to draw some recommendations for improving the JEFF library. 
(C/E -1) discrepancies for the AM241/U238 isotopic ratio for UOX fuels as a function of burnup

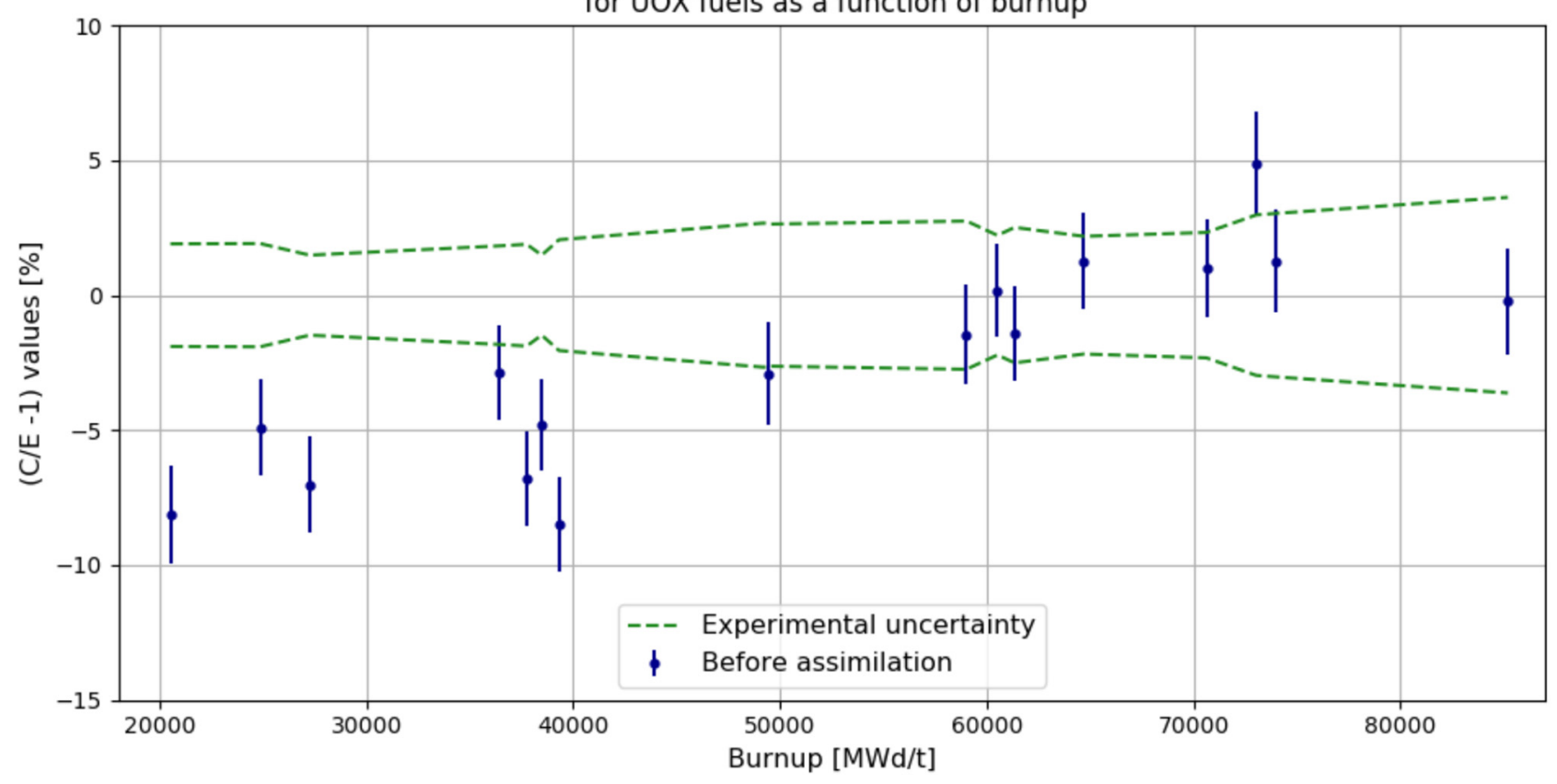

(C/E -1) discrepancies for the AM241/U238 isotopic ratio for UOX fuels as a function of burnup

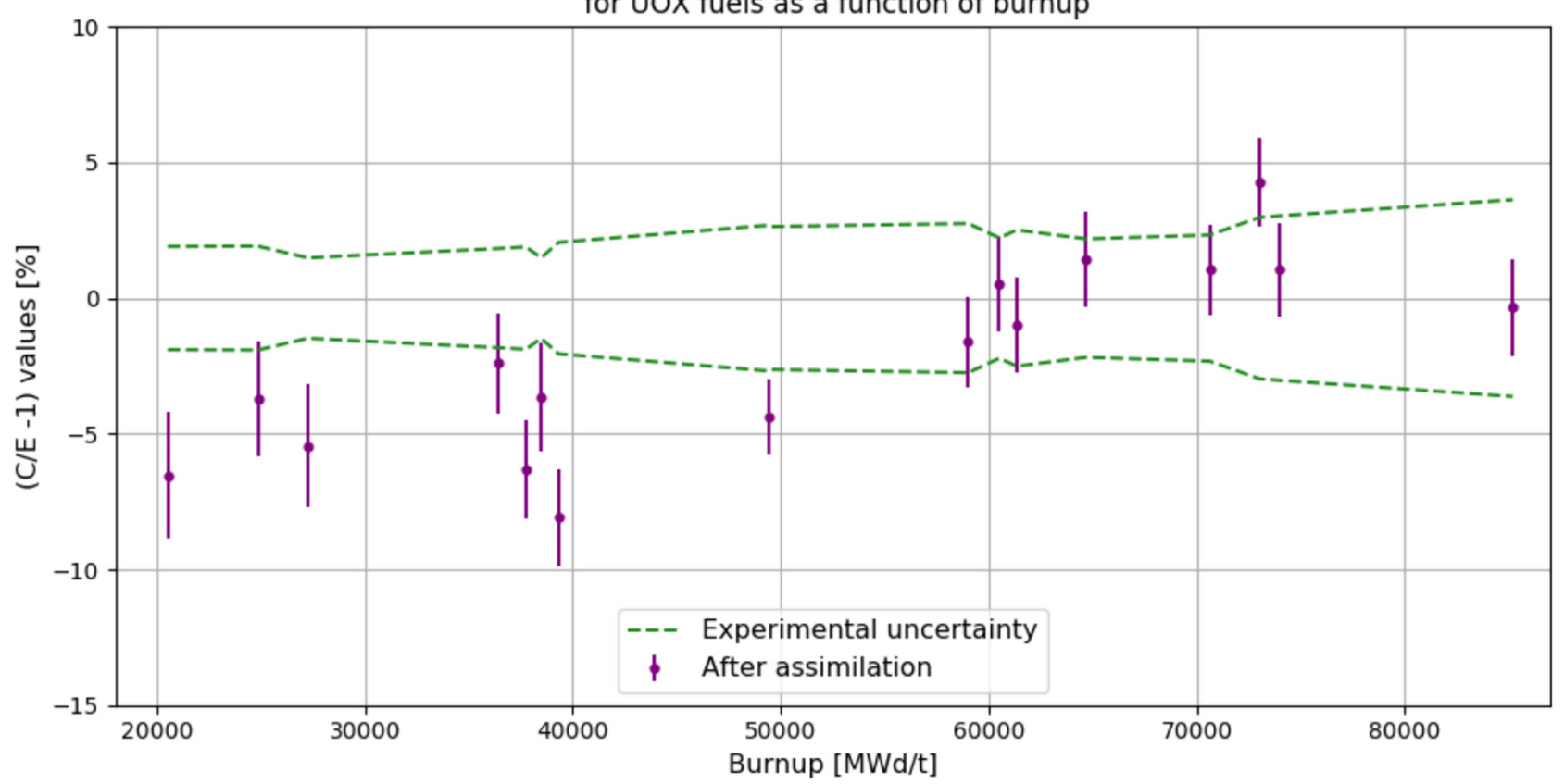

Fig. 5. Evolution of the calculated-to-experimental discrepancies before and after integral data assimilation for the ${ }^{241} \mathrm{Am} /{ }^{238} \mathrm{U}$ isotopic ratio in UOX fuels.

\subsection{Comparison with results reported in the literature}

Some examples of results available in the nuclear data literature for actinides and fission products are highlighted in Tables 5 and 6 . We have selected some works that provide nuclear data adjustment trends which are associated to the JEFF-3.1.1 library.

From an integral point of view, many oscillations and activation experiments were carried out in the MINERVE 
(C/E -1) discrepancies for the AM241/U238 isotopic ratio for MOX fuels as a function of burnup

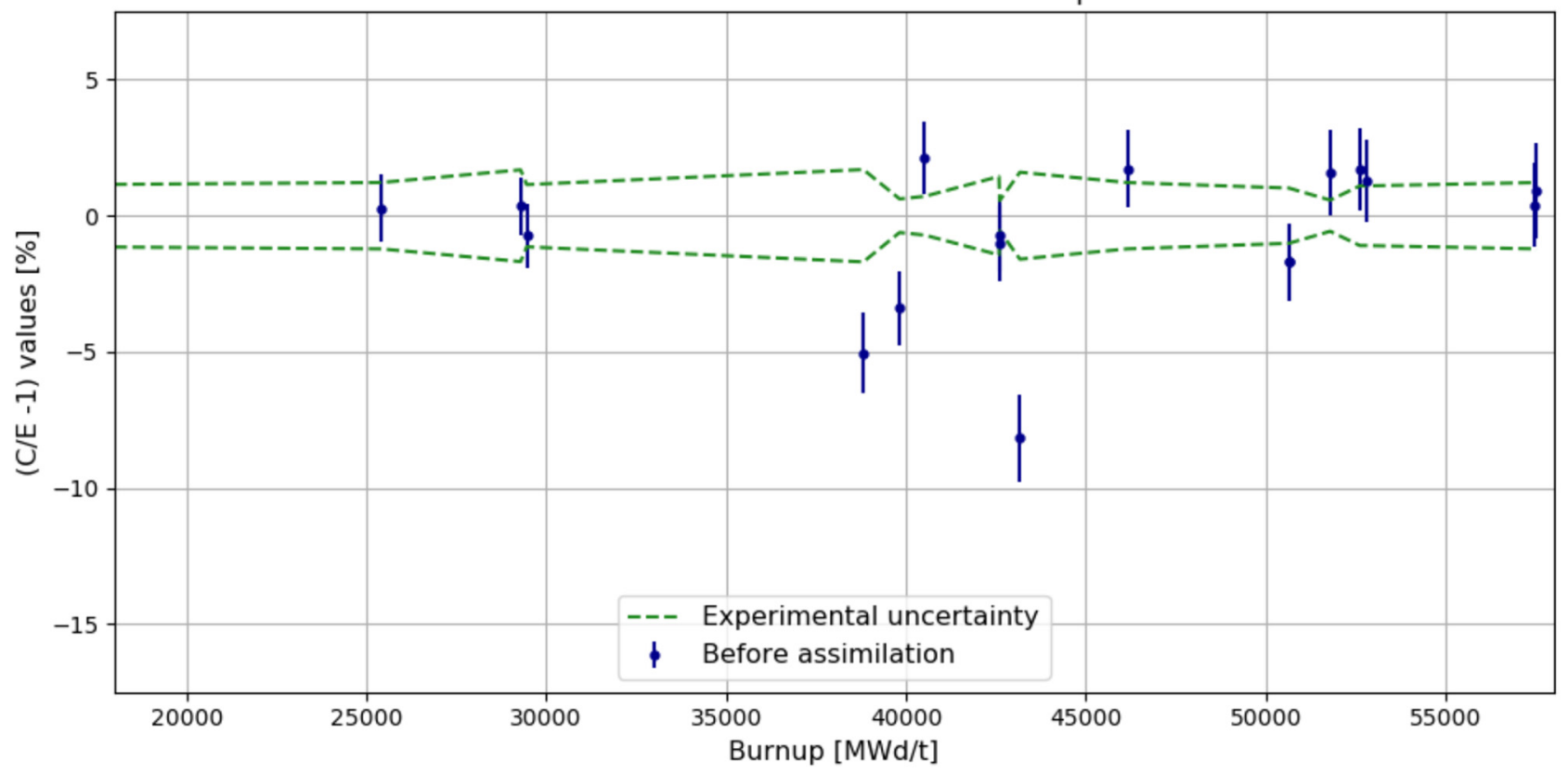

(C/E -1) discrepancies for the AM241/U238 isotopic ratio for MOX fuels as a function of burnup

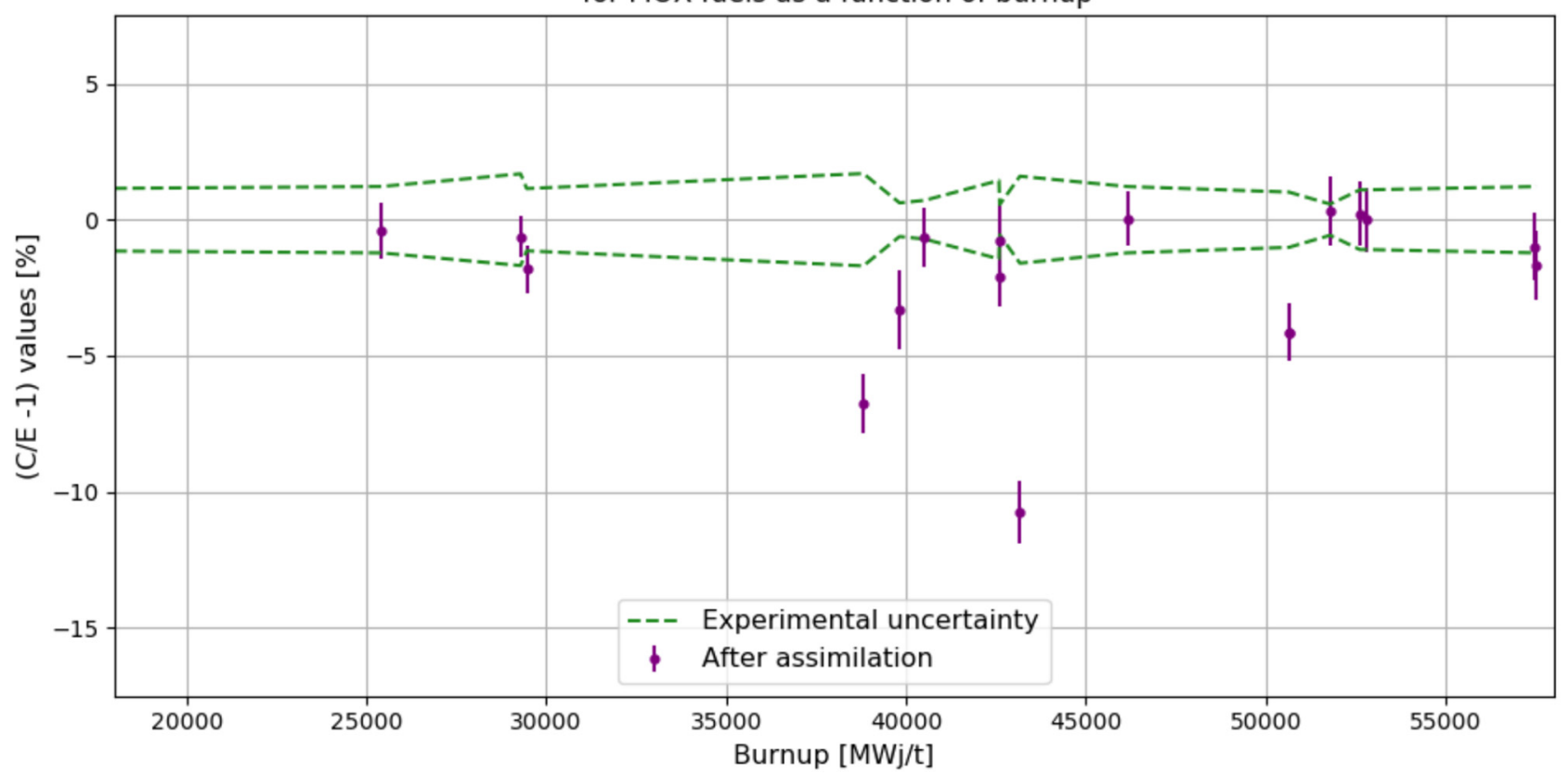

Fig. 6. Evolution of the calculated-to-experimental discrepancies before and after integral data assimilation for the ${ }^{241} \mathrm{Am} /{ }^{238} \mathrm{U}$ isotopic ratio in MOX fuels.

reactor of CEA Cadarache in order to obtain an insight on nuclear data adjustment trends for a large amount of isotopes. OSMOSE [20,21], CERES [22], BUC [23] and MAESTRO [24-26] are programs specifically dedicated to actinides, MOX fuels, fission products and structural materials respectively. PIEs of samples irradiated in thermal spectra (such as the ICARE and SHERWOOD programs carried out in the MELUSINE reactor of CEA Grenoble [27]) and in fast spectra (such as the PROFIL program carried out in the PHENIX reactor of CEA Marcoule [28]) provide integral information similar to used nuclear fuel data, namely isotopic ratios. One must pay attention that the reported $\mathrm{C} / \mathrm{E}-1$ values are not adjustment trends on nuclear data. This means that adjustment 


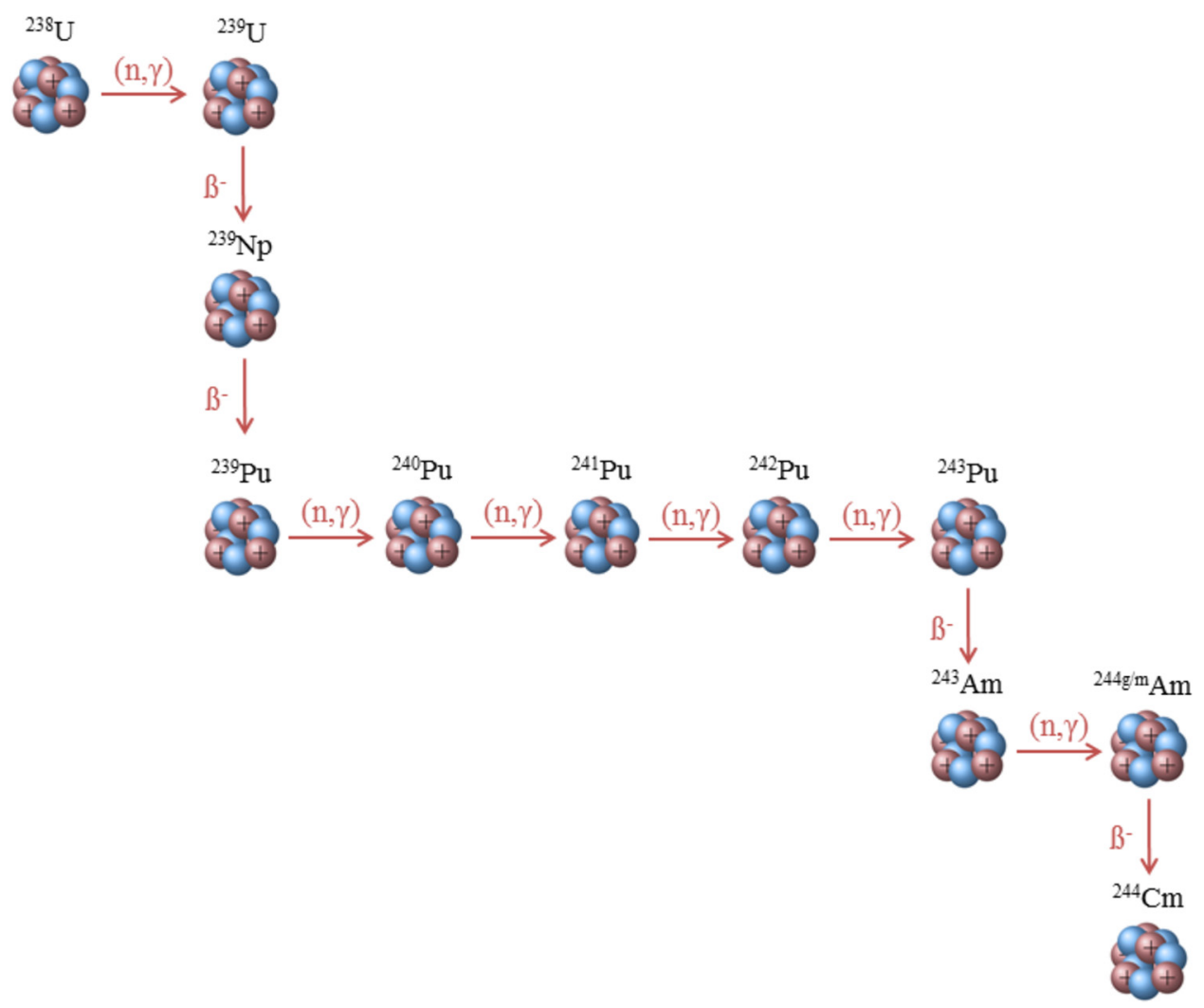

Fig. 7. Production chain of ${ }^{244} \mathrm{Cm}$.

trends obtained in the present work should compensate the $\mathrm{C} / \mathrm{E}-1$ values reported in Tables 5 and 6 (i.e. having opposed signs).

From a microscopic point of view, three time-of-flight experiments carried out in the past years for ${ }^{242} \mathrm{Pu}$ [29], ${ }^{243} \mathrm{Am} \mathrm{[30]} \mathrm{and}{ }^{153} \mathrm{Eu} \mathrm{[31]} \mathrm{at} \mathrm{the} \mathrm{n}_{-}$TOF and RPI facilities were considered. Resonance parameters extracted from these data provide useful information on the capture resonance integral. For the fission yields, results obtained at the ILL with the Lohengrin spectrometer [32-34] are listed.

From the evaluation point of view, it was chosen to focus on the case of ${ }^{103} \mathrm{Rh}$, for which a new evaluation has been recently performed at IRSN (Institut de Radioprotection et de Sûreté Nucléaire) with the SAMMY code [35].

In addition to the above-mentioned works, several studies were conducted based on the analyses of integral experiments. Two recent Integral Data Assimilation studies were performed on actinides with the RDN code using criticality-safety benchmarks in association to used nuclear fuel data [36], and integral data provided by the CERES program [22]. Posterior results are reported in Table 5. Finally, a nuclear data trend for the ${ }^{154} \mathrm{Eu}(\mathrm{n}, \gamma)$ reaction has been also obtained from the analysis of used nuclear fuel data [37]. Results are reported in Table 6 .

A detailed review of the results listed in Table 5 and 6 leads to three major conclusions.

- For the cumulative fission yields, trends suggested by our Integral Data Analysis are fully consistent with the ILL results. The agreement between the values remains within the limit of the reported uncertainties, which represents an encouraging result. An exhaustive comparison with a wider number of cumulative fission yields measured in various places could provide good indications about the robustness of our work.

- For the capture cross sections of the fission products, most of the reported results are also consistent, excepted those related to the ${ }^{103} \mathrm{Rh}(\mathrm{n}, \gamma)$ reaction. The large inconsistencies between the BUC and MAESTRO experiments carried out in the MINERVE reactor justify the replacement of the ${ }^{103} \mathrm{Rh}$ evaluation by a new evaluated nuclear data file, such as the one produced at IRSN [35].

- The last conclusion concerns the actinides for which the numerous inconsistencies observed between the reported integral data can lead to erroneous conclusions. For some reactions, this confused situation can be clarified with microscopic data, such as recent time-of-flight experiments carried out in the RPI and n TOF facilities. Examples given in Table 5 and 6 for the ${ }^{242} \mathrm{Pu}(\mathrm{n}, \gamma)$, ${ }^{243} \mathrm{Am}(\mathrm{n}, \gamma)$ and ${ }^{153} \mathrm{Eu}(\mathrm{n}, \gamma)$ reactions provide capture resonance integrals in favor of our Integral Data Assimilation results.

This comparative study indicates that our work provides consistent results for some actinides, fission products and cumulative fission yields; the present set of nuclear data adjustment trends represents a reliable guideline for improving the JEFF library. 
(C/E -1) discrepancies for the CM244/U238 isotopic ratio for UOX fuels as a function of burnup

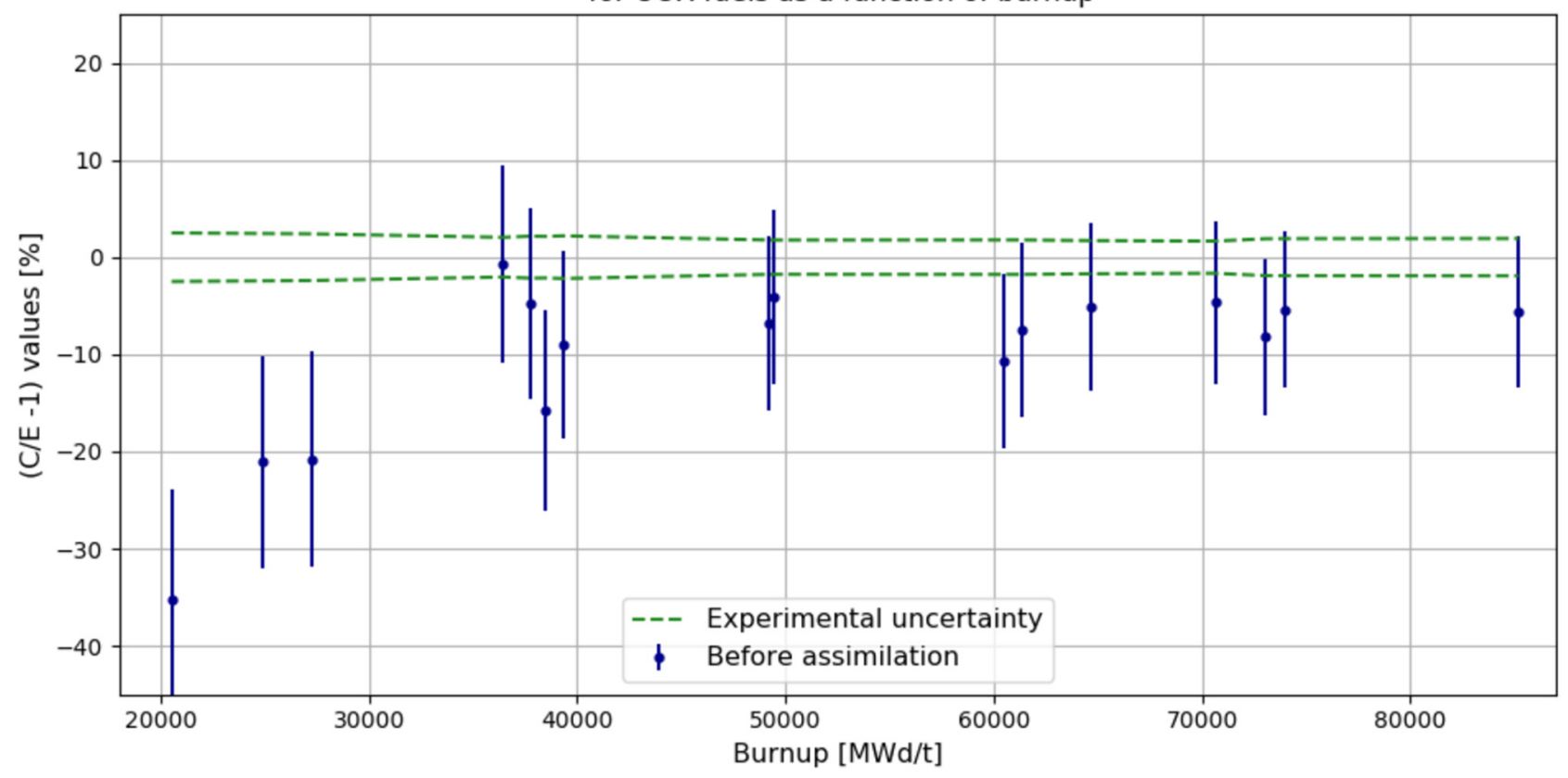

(C/E -1) discrepancies for the CM244/U238 isotopic ratio for UOX fuels as a function of burnup

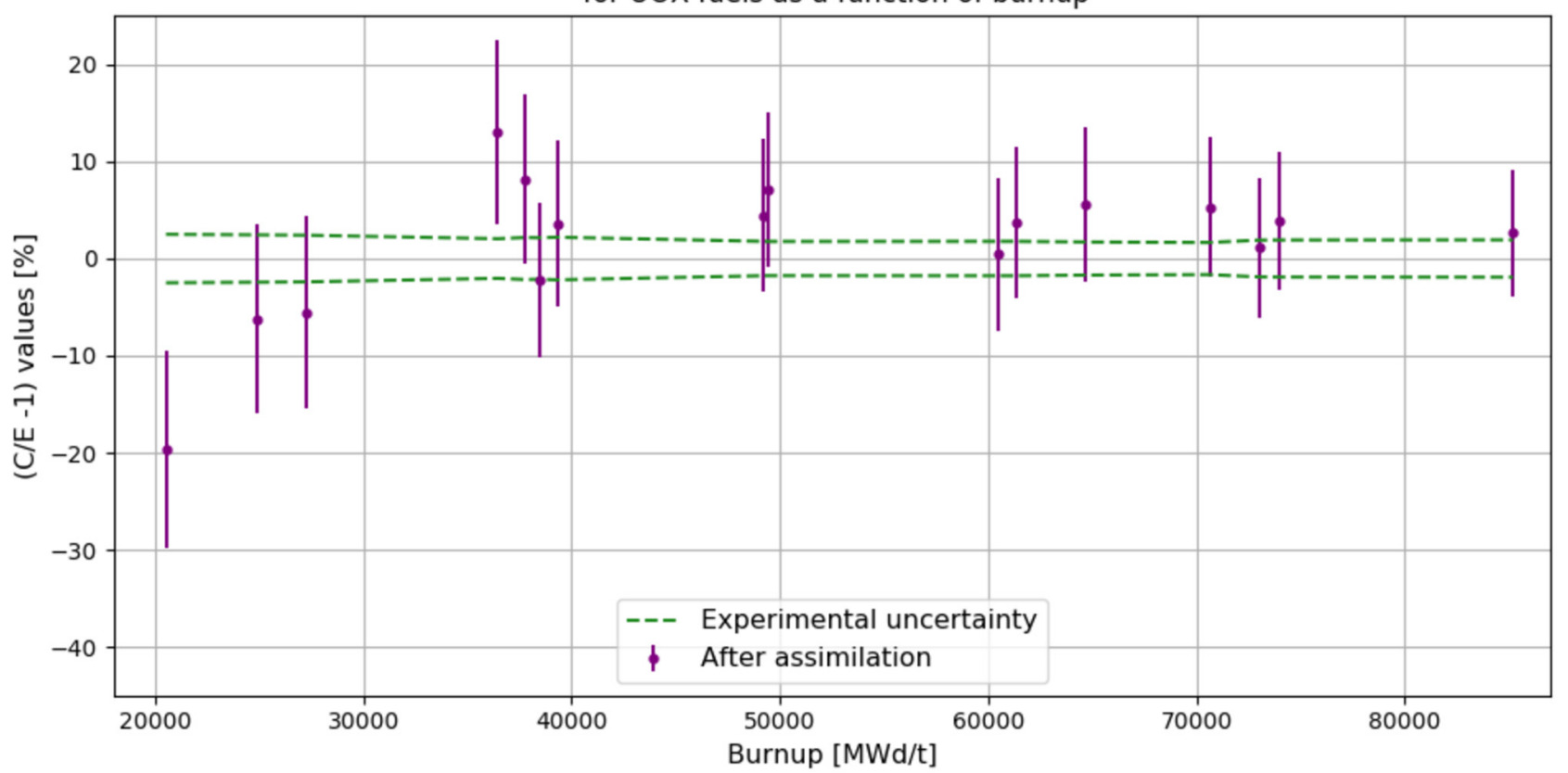

Fig. 8. Evolution of the calculated-to-experimental discrepancies before and after integral data assimilation for the ${ }^{244} \mathrm{Cm} /{ }^{238} \mathrm{U}$ isotopic ratio in UOX fuels.

\subsection{Recommended evaluated nuclear data files and resonance parameters}

The nuclear data adjustment trends suggested by our Integral Data Assimilation procedure can be used to propose cross section evaluations that could improve calculations related to the fuel cycle. Table 7 gives a list of recommended Evaluated Nuclear Data files or resonance parameters. We only consider capture reactions for which meaningful adjustment trends were obtained. Cumulative fission yields are not discussed because the evaluation process is more complex than the one for cross sections, since it generally relies on an experimental database containing a large number of independent and cumulative 

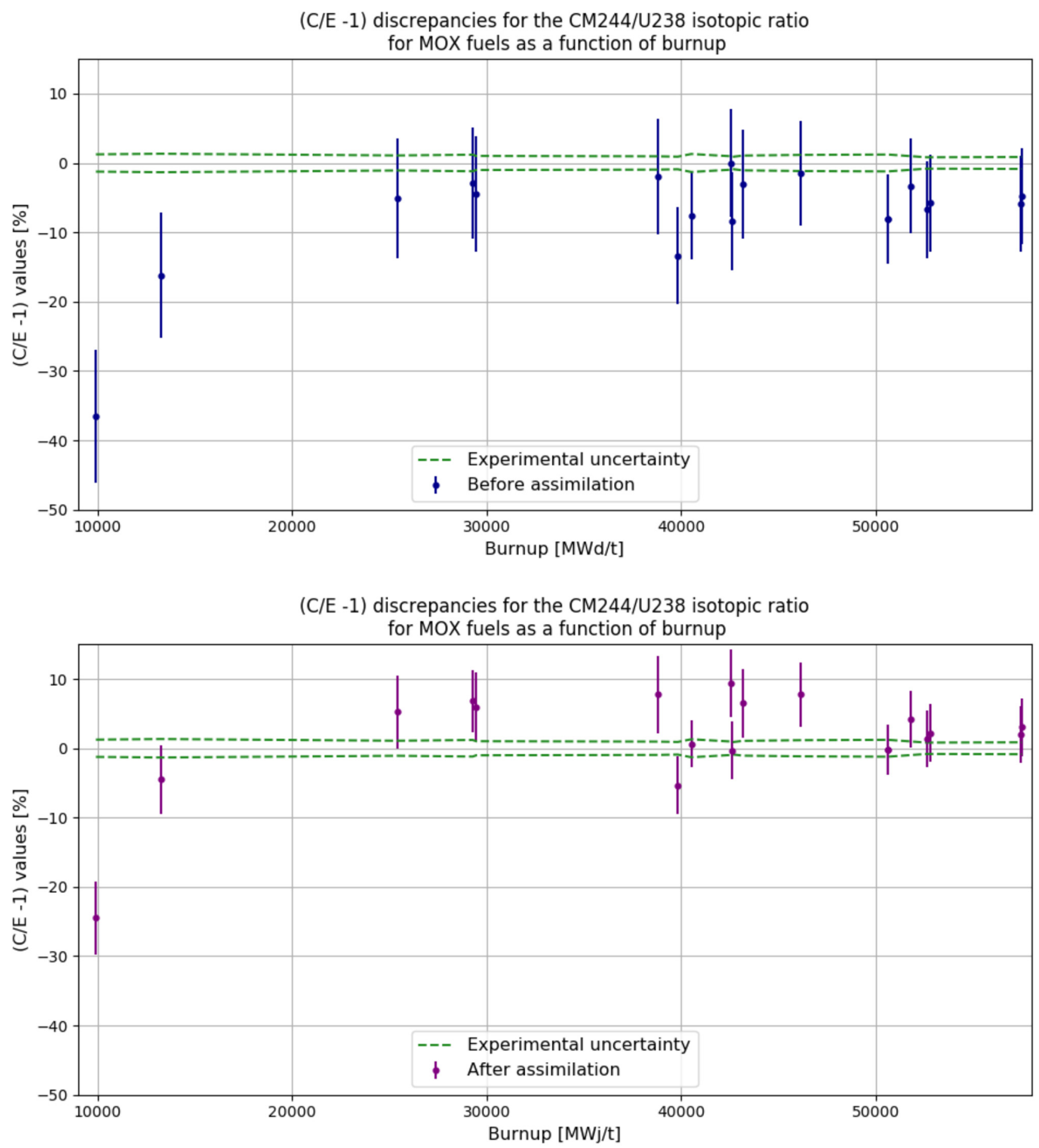

Fig. 9. Evolution of the calculated-to-experimental discrepancies before and after integral data assimilation for the ${ }^{244} \mathrm{Cm} /{ }^{238} \mathrm{U}$ isotopic ratio in MOX fuels.

fission yield measurements. Adjustment trends obtained on fission yields can nevertheless be used for the validation of the next fission yield evaluation releases.

Two types of recommendations can be distinguished. The first one consists in proposing existing Evaluated Nuclear Data files whose resonance parameters and neutron cross sections fulfil the nuclear data adjustment trends suggested by our study. This is the case for the ${ }^{236} \mathrm{U}$, ${ }^{238} \mathrm{U},{ }^{241} \mathrm{Am}$ and ${ }^{154} \mathrm{Eu}$ nuclides. The proposed evaluations come from new or old versions of the JEFF library or from the Japanese library JENDL-4.0. Justifications of these choices are given in Table 7 . One can precise that the recommended evaluation for ${ }^{154} \mathrm{Eu}$ capture cross-section relies on a work carried out in [40], which aims at assessing 


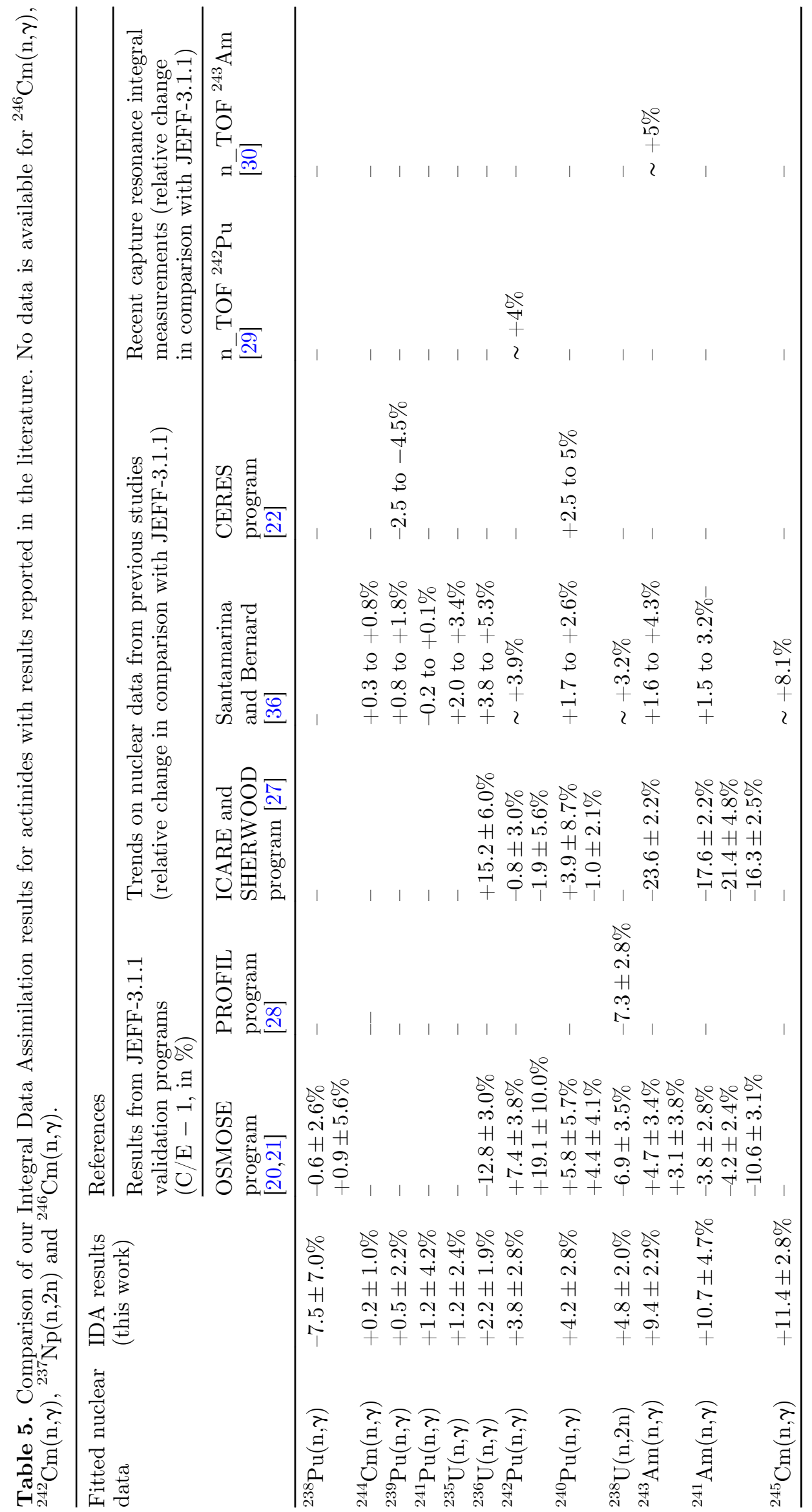




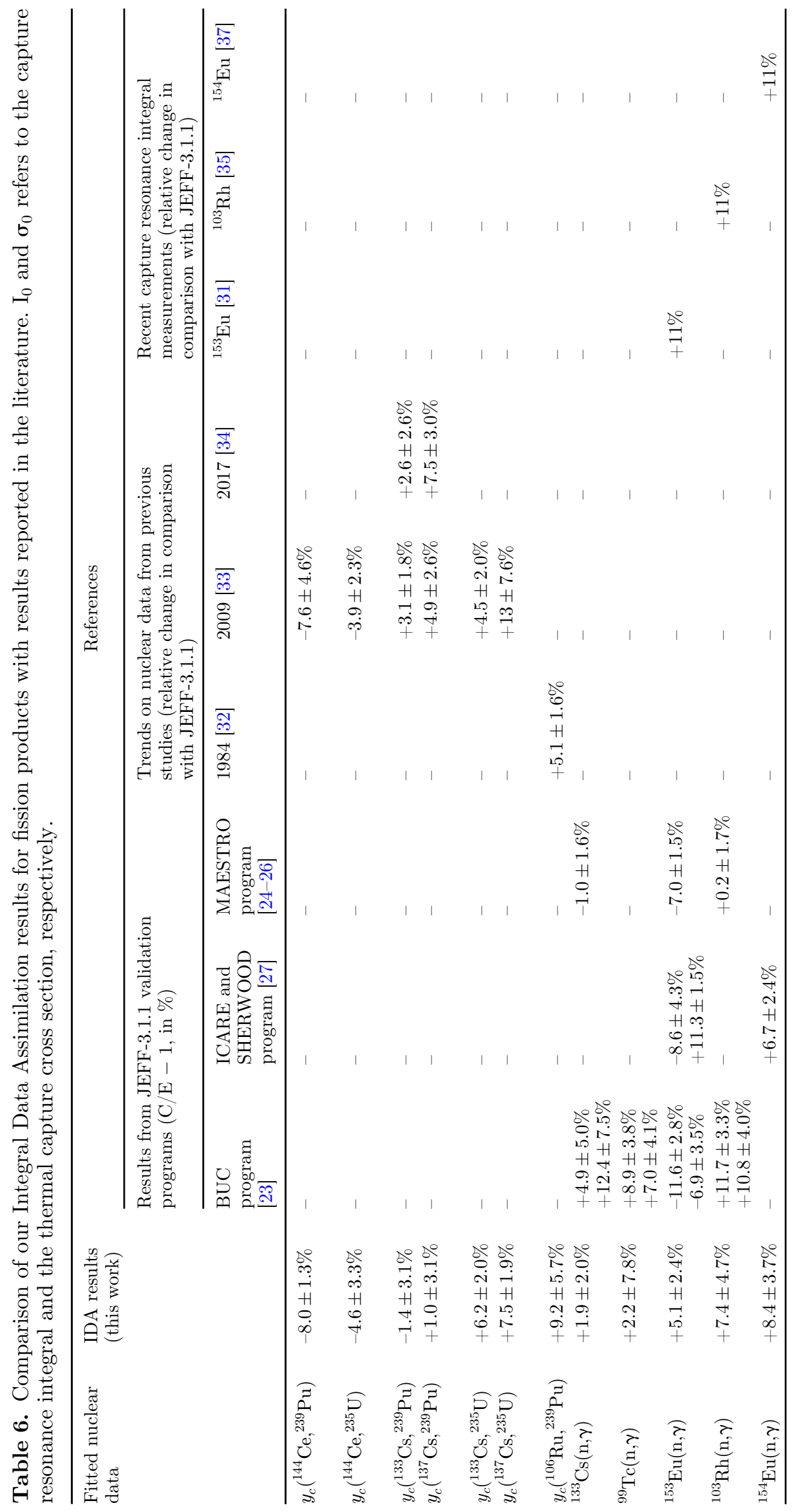


Table 7. Evaluated nuclear data files and new resonance parameters in agreement with the nuclear data adjustment trends provided by our Integral Data Assimilation study.

\begin{tabular}{|c|c|c|c|}
\hline $\begin{array}{l}\text { Fitted nuclear } \\
\text { data }\end{array}$ & IDA results & $\begin{array}{l}\text { Recommended evaluation } \\
\text { or resonance parameters }\end{array}$ & Comments \\
\hline${ }^{236} \mathrm{U}(\mathrm{n}, \gamma)$ & $+2.2 \pm 1.9 \%$ & JENDL-4.0 & $\begin{array}{l}\text { JENDL- } 4.0 \text { suggests an increase of }+2 \% \text { of the capture } \\
\text { resonance integral. }\end{array}$ \\
\hline${ }^{242} \mathrm{Pu}(\mathrm{n}, \gamma)$ & $+3.8 \pm 2.8 \%$ & $\begin{array}{l}\text { Resonance parameters } \\
\text { from reference }[29]\end{array}$ & $\begin{array}{l}\text { Recent time-of-flight measurements carried out at the } \\
\mathrm{n}_{\text {_TOF facility }} \\
\text { propose an increase of about }+4 \% \text { of the capture } \\
\text { resonance integral. }\end{array}$ \\
\hline${ }^{240} \mathrm{Pu}(\mathrm{n}, \gamma)$ & $+4.2 \pm 2.8 \%$ & $\begin{array}{l}\text { Resonance parameters } \\
\text { from reference [39] }\end{array}$ & $\begin{array}{l}\text { Recent resonance analysis suggests a slight increase } \\
\text { of about }+0.6 \% \text { of the capture area of the 1st resonance. }\end{array}$ \\
\hline${ }^{238} \mathrm{U}(\mathrm{n}, 2 \mathrm{n})$ & $+4.8 \pm 2.0 \%$ & JEFF-3.3 [38] & JEFF-3.3 suggests an increase of about $+3 \%$. \\
\hline${ }^{243} \operatorname{Am}(\mathrm{n}, \gamma)$ & $+9.4 \pm 2.2 \%$ & $\begin{array}{l}\text { Resonance parameters } \\
\text { from reference [30] }\end{array}$ & $\begin{array}{l}\text { As discussed in Section } 5 \text {, the obtained trend seems } \\
\text { to be too high. }\end{array}$ \\
\hline${ }^{241} \mathrm{Am}(\mathrm{n}, \gamma)$ & $+10.7 \pm 4.7 \%$ & $\begin{array}{l}\text { JEFF-3.3 [38] (taken } \\
\text { from JEFF-3.2) }\end{array}$ & $\begin{array}{l}\text { The capture cross section was already improved } \\
\text { in the JEFF-3.2 library. }\end{array}$ \\
\hline${ }^{153} \mathrm{Eu}(\mathrm{n}, \gamma)$ & $+5.1 \pm 2.4 \%$ & $\begin{array}{l}\text { Resonance parameters } \\
\text { from reference [31] }\end{array}$ & $\begin{array}{l}\text { Resonance parameters extracted from RPI data are } \\
\text { in agreement with our study. } \\
\text { Possible improvements were already addressed } \\
\text { in a previous study [9]. }\end{array}$ \\
\hline${ }^{103} \operatorname{Rh}(\mathrm{n}, \gamma)$ & $+7.4 \pm 4.7 \%$ & $\begin{array}{l}\text { Resonance parameters } \\
\text { from reference [35] }\end{array}$ & $\begin{array}{l}\text { New resonance analysis, performed at IRSN Fontenay } \\
\text { aux Roses, suggests an increase of }+11 \% \\
\text { of the capture resonance integral, which is consistent } \\
\text { with our results. }\end{array}$ \\
\hline${ }^{154} \mathrm{Eu}(\mathrm{n}, \gamma)$ & $+8.4 \pm 3.7 \%$ & JEFF-3.0 & $\begin{array}{l}\text { The analysis from reference }[40] \text { suggests to use } \\
\text { the resonance } \\
\text { parameters of JEFF- } 3.0\end{array}$ \\
\hline
\end{tabular}

the impact of different nuclear data evaluations on Europium isotopes build-up with the DARWIN package. This study showed that best results are obtained using JEFF-3.0 for ${ }^{154} \mathrm{Eu}$ capture cross section, which exhibits changes on the first resonance parameters that induce a higher thermal capture cross-section compared to JEFF3.1.1. The second type of recommendations consists in selecting resonance parameters which are not yet available in an official neutron library. Parameters could be retrieved from recent publications [29-31] for ${ }^{242} \mathrm{Pu},{ }^{243} \mathrm{Am}$, and ${ }^{153} \mathrm{Eu}$, and introduced in an Evaluated Nuclear Data file for further validation studies, or they could come from recent resonance analyses for ${ }^{240} \mathrm{Pu}$ and ${ }^{103} \mathrm{Rh}$. The latter are usually preliminary works that provide encouraging results.

\section{Conclusions}

In this paper, comparisons of calculated and experimental isotopic compositions of used nuclear fuels are carried out to provide information on the accuracy of nuclear data from the JEFF-3.1.1 library for fuel cycle applications. The method applied relies on both a fitting algorithm and a marginalization procedure implemented in the CONRAD code.
Final results confirm the accuracy of ${ }^{235} \mathrm{U},{ }^{239} \mathrm{Pu}$ and ${ }^{241} \mathrm{Pu}$ neutron capture cross sections available in the JEFF3.1.1 library. Slight increases of $+1.2 \pm 2.4 \%,+0.5 \pm 2.2 \%$ and $+1.2 \pm 4.2 \%$ are respectively suggested, these all remaining within the limit of the quoted uncertainties. Results indicate the good quality of ${ }^{236} \mathrm{U},{ }^{244} \mathrm{Cm},{ }^{246} \mathrm{Cm}$ and ${ }^{133} \mathrm{Cs}$ capture cross sections as well, since the adjustment trends obtained remain within the quoted uncertainties. Our study also suggest to slightly increase ${ }^{238} \mathrm{U}(\mathrm{n}, 2 \mathrm{n})$, ${ }^{240} \mathrm{Pu}(\mathrm{n}, \gamma)$ and ${ }^{242} \mathrm{Pu}(\mathrm{n}, \gamma)$, adjustment trends obtained being lower than $+5 \%$. Adjustment trends greater than $+5 \%$ are obtained for ${ }^{237} \mathrm{~Np}(\mathrm{n}, 2 \mathrm{n}),{ }^{241} \mathrm{Am}(\mathrm{n}, \gamma),{ }^{243} \mathrm{Am}$ $(\mathrm{n}, \gamma),{ }^{242} \mathrm{Cm}(\mathrm{n}, \gamma),{ }^{245} \mathrm{Cm}(\mathrm{n}, \gamma),{ }^{247} \mathrm{Cm}(\mathrm{n}, \gamma),{ }^{153} \mathrm{Eu}(\mathrm{n}, \gamma)$, ${ }^{154} \mathrm{Eu}(\mathrm{n}, \gamma)$ and ${ }^{103} \operatorname{Rh}(\mathrm{n}, \gamma)$.

Meaningful adjustment trends for the cumulative fission yields of ${ }^{144} \mathrm{Ce},{ }^{133} \mathrm{Cs},{ }^{137} \mathrm{Cs}$ and ${ }^{106} \mathrm{Ru}$ for the ${ }^{235} \mathrm{U}\left(\mathrm{n}_{\mathrm{th}}, \mathrm{f}\right)$ and ${ }^{239} \mathrm{Pu}\left(\mathrm{n}_{\mathrm{th}}, \mathrm{f}\right)$ reactions, ranging from $-8 \%$ to $+9 \%$ approximately, are also reported.

Comparisons with data from the literature show a good agreement of the adjustment trends obtained on cumulative fission yields with experiments recently conducted at the ILL facility, and show a global agreement of the adjustment trends obtained on neutron cross sections with integral and microscopic experiments carried out in the past. Based on these results, several cross section evaluation are recommended to improve fuel cycle 
calculations: these evaluations may come from other international libraries or be based on resonance parameters recently measured at time-of-flight facilities. The evaluations recommended in this paper represent a valuable feedback of the fuel cycle applications that can be used for the improvement of the future JEFF library releases and more generally for the improvement of nuclear data.

Authors would like to thank Orano for its support and Luiz Leal for providing resourceful information on the ${ }^{103} \mathrm{Rh}$ evaluation. Special acknowledgements go to colleagues from CEA for their valuable help during this work, especially David Bernard, Coralie Carmouze, Vanessa Vallet and Pascal Archier.

\section{References}

1. L. San-Felice et al., Experimental validation of the DARWIN2.3 package for fuel cycle applications, Nucl. Technol. 184, 217 (2013)

2. A. Santamarina et al., APOLLO2.8: a validated code package for PWR calculations, in Proc. Int. Conf. Advances in Nuclear Fuel Management IV, Hilton Head Island, South Carolina USA, 2009

3. A. Tsilanizara et al., DARWIN: an evolution code system for a large range of applications, in Proc. Int. Conf. ICRS-9, Tsukuba, Ibakari, Japan, 1999

4. A. Santamarina et al., The JEFF-3.1.1 Nuclear Data library", JEFF report, 22, OECD-NEA Data Bank, 2009

5. C. de Saint Jean et al., Status of CONRAD, a nuclear reaction analysis tool, in Proc. Int. Conf. Nuclear Data for Science and Technology, Nice, France, 2007

6. P. Archier et al., CONRAD evaluation code: development status and perspectives, in Proc. Int. Conf. Nuclear Data for Science and Technology, New-York, USA, 2013

7. A. Rizzo et al., Work plan for improving the DARWIN2.3 depleted material balance calculation of nuclides of interest for the fuel cycle, EPJ Web Conf. 146, 09030 (2017)

8. A. Rizzo et al., Nuclear data Adjustment based on the interpretation of post-irradiation experiments with the DARWIN2.3 package, EPJ Nuclear Sci. Technol. 4, 47 (2018)

9. A. Rizzo et al., Assessment of the ${ }^{153} \mathrm{Eu}$ and ${ }^{154} \mathrm{Eu}$ neutron capture cross sections from the Integral Data Assimilation of used nuclear fuel experiments, Ann. Nucl. Energy 124, 524 (2019)

10. C. Bastian et al., AGS, a computer code for uncertainty propagation in time-of-flight cross-section data, in Proc. Int. Conf. PHYSOR, Vancouver, Canada, 2006

11. B. Habert et al., Retroactive generation of covariance matrix of nuclear model parameters using marginalization techniques, Nucl. Sci. Eng. 166, 276 (2010)

12. G. Noguere et al., Zero variance penalty model for the generation of covariance matrices in integral data assimilation problems, Nucl. Sci. Eng. 172, 164 (2012)

13. E. Privas et al., Generation of ${ }^{238} \mathrm{U}$ covariance matrices by using the integral data assimilation technique of the CONRAD code, EPJ Web Conf. 106, 04015 (2016)

14. I.C. Gauld et al., Uncertainties in predicted isotopic compositions for high burnup PWR spent nuclear fuel, U.S. NRC report NUREG/CR-7012, ORNL/TM-2010/41, 2010
15. E. Brun et al., TRIPOLI- $4^{\circledR}$, CEA, EDF, and AREVA reference Monte Carlo code, Ann. Nucl. Energy 82, 151 (2015)

16. M. Ouisloumen et al., A model for neutron scattering off heavy isotopes that accounts for thermal agitation effects, Nucl. Sci. Eng. 107, 189 (1991)

17. V. Vallet et al., Deterministic approach of the decay heat uncertainty due to JEFF-3.1.1 nuclear data uncertainties with the CYRUS tool and the DARW IN2. 3 depletion code, Proc. Int. Conf. PHYSOR, Kyoto, Japan, 2014

18. P. Archier et al., COMAC - Nuclear data covariance matrices library for reactor applications, Proc. Int. Conf. PHYSOR, Kyoto, Japan, 2014

19. N. Terranova, Covariance Evaluation for Nuclear Data of Interest to the Reactivity Loss Estimation of the Jules Horowitz Reactor, Ph.D. thesis report, Bologne University, Italy, 2016

20. D. Bernard et al., Validation of actinides nuclear cross section using pile-oscillation experiments performed at MINERVE facility, J. Korean Phys. Soc. 59, 1119 (2011)

21. P. Leconte et al., OSMOSE programme: validation of actinides nuclear data for LWR applications, JEFDOC1502, OECD NEA Data Bank, 2013

22. P. Leconte et al., Feedback on ${ }^{239} \mathrm{Pu}$ and ${ }^{240} \mathrm{Pu}$ nuclear data and associated covariances through the CERES integral experiments, J. Nucl. Sci. Technol. 52, 1044 (2015)

23. A. Gruel et al., Interpretation of fission products oscillations in the MINERVE reactor, from thermal to epithermal spectra, Nucl. Sci. Eng. 169, 229 (2011)

24. P. Leconte et al., MAESTRO: an ambitious experimental programme for the improvement of nuclear data of structural, detection, moderating, and absorbing materials - first results for ${ }^{\text {nat }} \mathrm{V},{ }^{55} \mathrm{Mn},{ }^{59} \mathrm{Co}$, and ${ }^{103} \mathrm{Rh}$, in Proc. Int. Conf. ANIMMA, Marseille, France, 2013

25. P. Leconte et al., Thermal neutron activation experiments on $\mathrm{Ag}, \mathrm{In}, \mathrm{Cs}, \mathrm{Eu}, \mathrm{V}, \mathrm{Mo}, \mathrm{Zn}, \mathrm{Sn}$ and $\mathrm{Zr}$ in the MINERVE facility, EPJ Web Conf. 111, 07001 (2016)

26. P. Leconte et al., Nuclear data feedback on structural, moderating and absorbing materials through the MAESTRO experimental programme, JEFDOC-1849, OECD NEA Data Bank, 2017

27. D. Bernard et al., Validation of JEFF-3.1.1 thermal and epithermal induced capture cross sections through MELUSINE experiment analysis, Nucl. Sci. Eng. 179, 302 (2015)

28. J.-F. Lebrat et al., JEFF-3.1.1 nuclear data validation for sodium fast reactors, J. Nucl. Sci. Technol. 48, 620 (2011)

29. J. Lerendegui-Marco et al., Radiative neutron capture of ${ }^{242} \mathrm{Pu}$ in the resonance region at the CERN n_TOF-EAR1 facility, Phys. Rev. C 97, 024605 (2018)

30. E. Mendoza et al., Measurement and analysis of the ${ }^{243} \mathrm{Am}$ neutron capture cross section at the n_TOF facility at CERN, Phys. Rev. C 90, 036608 (2014)

31. G. Leinweber et al., Europium resonance parameters from neutron capture and transmission measurements in the energy range 0.01-200 eV, Ann. Nucl. Energy 69, 74 (2014)

32. C. Schmitt et al., Fission yield at different fission-product kinetic energies for thermal-neutron-induced fission on ${ }^{239} \mathrm{Pu}$, Nucl. Phys. A 940, 21 (1984) 
33. A. Bail, Mesures de rendements isobariques et isotopiques des produits de fission lourds sur le spectrumètre de masse Lohengrin, Ph.D thesis, University of Bordeaux, France, 2009

34. Y. Gupta et al., Fission fragment yield distribution in the heavy-mass region from the ${ }^{239} \mathrm{Pu}\left(\mathrm{n}_{\mathrm{th}}, \mathrm{f}\right)$ reaction, Phys. Rev. C 96, 014608 (2017)

35. L. Leal et al., Nuclear data evaluation work at IRSN, JEFDOC-1832, OECD NEA Data Bank, 2017

36. A. Santamarina, D. Bernard et al., Re-estimation of nuclear data and reliable covariances using integral experiments. Application to JEFF3 library, in Proc. Int. Conf. on Mathematicals \& Computational methods applied to nuclear science and engineering, Jeju, South Korea, 2017

37. S.E. Skutnik, Proposed re-evaluation of the ${ }^{154} \mathrm{Eu}$ thermal $(\mathrm{n}, \gamma)$ capture cross-section based on spent fuel nuclear benchmarking studies, Ann. Nucl. Energy 99, 80 (2017)

38. JEFF-3.3 nuclear data library, available at www.oecd-nea. org/dbdata/JEFF33/ (2018)

39. G. Noguere et al., New resonance parameters shape analysis of the $1^{\text {st }}$ resonance of Pu240 for thermal reactor applications, JEFDOC-1526, OECD NEA Data Bank, 2013

40. G. Noguere, P.H.L. Doan, Progress report on ${ }^{154}$ Eu buildup for DARWIN applications, JEFDOC-1592, OECD NEA Data Bank, 2014

Cite this article as: Axel Rizzo, Claire Vaglio-Gaudard, Gilles Noguere, Romain Eschbach, Gabriele Grassi, Julie-Fiona Martin, Feedback from experimental isotopic compositions of used nuclear fuels on neutron cross sections and cumulative fission yields of the JEFF-3.1.1 library by using integral data assimilation, EPJ Nuclear Sci. Technol. 5, 24 (2019) 